\title{
Imaging of non-neuronopathic Gaucher disease: recent advances in quantitative imaging and comprehensive assessment of disease involvement
}

\author{
Andrew J. Degnan ${ }^{1,2^{*}}$, Victor M. Ho-Fung ${ }^{1,2}$, Rebecca C. Ahrens-Nicklas ${ }^{3,4}$, Christian A. Barrera ${ }^{1}$, Suraj D. Serai ${ }^{1}$, \\ Dah-Jyuu Wang ${ }^{1}$ and Can Ficicioglu li,4 $^{3,2}$
}

\begin{abstract}
Gaucher disease is an inherited metabolic disorder resulting in deficiency of lysosomal enzyme $\beta$ glucocerebrosidase causing the accumulation of abnormal macrophages ("Gaucher cells") within multiple organs, most conspicuously affecting the liver, spleen, and bone marrow. As the most common glycolipid metabolism disorder, it is important for radiologists encountering these patients to be familiar with advances in imaging of organ and bone marrow involvement and understand the role of imaging in clinical decision-making. The recent advent of commercially available, reliable, and reproducible quantitative MRI acquisitions to measure fat fractions prompts revisiting the role of quantitative assessment of bone marrow involvement. This manuscript reviews the diverse imaging manifestations of Gaucher disease and discusses more optimal quantitative approaches to ascertain solid organ and bone marrow involvement with an emphasis on future applications of other quantitative methods including elastography.
\end{abstract}

Keywords: Gaucher disease, Lysosomal storage disorder, Bone marrow infiltration, Quantitative MRI, Treatment monitoring

\section{Key points}

- Non-neuronopathic Gaucher disease most conspicuously involves bone marrow, liver, and spleen.

- Organ volumes are commonly used for disease severity and treatment response.

- Anatomic imaging is relatively insensitive to marrow infiltration in Gaucher disease.

- Quantitative marrow fat-fractions indicate musculoskeletal severity and show early treatment response.

- Elastography may aid in assessing fibrosis in Gaucher disease.

\footnotetext{
* Correspondence: degnana@email.chop.edu

'Department of Radiology, Children's Hospital of Philadelphia, 3401 Civic Center Blvd., Philadelphia, PA 19104, USA

${ }^{2}$ Department of Radiology, Perelman School of Medicine at the University of Pennsylvania, 3400 Civic Center Blvd., Philadelphia, PA 19104, USA

Full list of author information is available at the end of the article
}

\section{Background}

Classification of Gaucher disease

As the most common lysosomal storage disorder, Gaucher disease manifests with abnormal accumulation of glucosylceramide within macrophage lysosomes in multiple organs resulting from an absence or deficiency of $\beta$-glucocerebrosidase (also termed $\beta$-glucosidase, a glycosphingolipid) enzyme activity [1,2]. This disease is inherited in an autosomal recessive fashion with over 350 mutations in the glucosylcerebrosidase $(G B A)$ gene identified to-date [3].

Although this condition is attributed to a single gene, there is substantial variability in the phenotypic presentation of Gaucher disease with three classically described types [3]. This article focuses on the chronic, non-neuronopathic form (type 1), manifesting with prominent involvement of the reticuloendothelial system with liver, spleen, and marrow involvement, whereas the other types (acute neuronopathic type 2 and subacute-chronic 
neuronopathic type 3, summarized in Table 1) are far less common [4]. It is worth noting that some experts propose conceptualizing these disease types as a phenotypic spectrum rather than as distinct entities. Some work has suggested subclinical neurological involvement in the "non-neuronopathic" type with abnormal brain magnetic resonance spectroscopy (MRS) findings reported in type 1 Gaucher disease patients, although subsequent investigations have failed to replicate these observations and further work is needed $[5,6]$. Others have suggested an increased risk of Parkinsonism in individuals with GBA mutations that reflects a complex relationship between glucocerebrosidase and Lewy body disorders [7].

While type 1 Gaucher disease is most often diagnosed in childhood or early adulthood with a little under one-third of cases diagnosed by 10 years of age [8], this condition can come to clinical attention at any age due to gradations of residual enzyme activity and phenotypic variability [9]. Pediatric phenotypic expression, however, tends to be particularly severe [10]. The diversity of clinical manifestation and spectrum of disease severity underscore the importance of accurate assessment of multisystemic involvement at diagnosis and across the lifespan [9]; as this article will further discuss, diagnostic imaging plays an instrumental role in clinical evaluation and management of Gaucher disease.

\section{Epidemiology, clinical evaluation, and treatment}

While Gaucher disease is relatively uncommon overall with an estimated prevalence of approximately $1 / 40,000$, certain groups have much higher carrier and disease prevalence with a carrier frequency of as high as $6-10 \%$ in Ashkenazi Jewish individuals $[11,12]$. The majority of type 1 Gaucher disease patients are diagnosed during childhood, and type 1 Gaucher disease is most commonly due to biallelic p.N370S mutations in the Western world [4].

Detailed description of the diagnostic workup and clinical management of Gaucher disease is beyond the scope of this article, but it is helpful for radiologists evaluating patients with Gaucher disease to be familiar with commonly utilized clinical tests and available therapies. Laboratory tests and biomarkers are summarized in Table 2; these clinical tests are part of comprehensive patient assessment that also involves diagnostic imaging. Clinical severity scoring is often performed using the Gaucher Disease Type 1 Severity Scoring System (GD-DS3) [13], which incorporates bone involvement, hematologic parameters, and organ enlargement. The Pediatric Gaucher Severity Scoring System (PGS3) [14] additionally accounts for growth disturbance as a key consideration in the younger population.

Traditionally, Gaucher disease has been conceptualized as a single gene-related disease due to one enzyme with one treatment consisting of enzyme replacement therapy (ERT) [3]. Prior to the advent of ERT, treatment was largely based on addressing symptoms with splenectomy performed for extensive splenic infiltration in severe patients with poor prognosis. The earliest effective ERT, alglucerase, was introduced in the 1990s and has dramatically changed the prognosis of this condition. Subsequent newer forms of ERT with improved manufacturing techniques and safety profiles have been approved. Newer oral substrate reduction therapy (SRT) functions earlier in the biochemical pathway by mitigating the accumulation of glucosylceramide [15]. Both types of therapies are expensive, and each have disadvantages to consider with ERT requiring intravenous infusion every few weeks and SRT possessing a narrower safety profile with CYP2D6 and CYP3A metabolism considerations as well as being only approved for adult use [3, 4, 16]. Historic and currently available treatment options are summarized in Table 3, but we refer interested readers elsewhere for detailed description of clinical trials and advances in Gaucher disease treatment [17].

Many asymptomatic patients with mild disease may not receive treatment at first; most children with milder genotypes perhaps may not require treatment initially.

Table 1 Clinical classifications of Gaucher disease

\begin{tabular}{|c|c|c|c|c|c|c|}
\hline Type & Name & Dominant clinical manifestations & Predilections & Age of onset & Life expectancy & Treatment \\
\hline 1 & $\begin{array}{l}\text { Chronic, non- } \\
\text { neuronopathic }\end{array}$ & $\begin{array}{l}\text { Prominent visceral involvement } \\
\text { Anemia, bleeding predilection } \\
\text { Osseous manifestations } \\
\text { (avascular necrosis, fracture) } \\
\text { Growth impairment }\end{array}$ & $\begin{array}{l}\text { N370S } \\
\text { mutations } \\
\text { Ashkenazi Jews }\end{array}$ & $\begin{array}{l}\text { Variable (childhood- } \\
\text { early adulthood) }\end{array}$ & Normal to almost-normal & $\begin{array}{l}\text { ERT or SRT for } \\
\text { symptomatic patients }\end{array}$ \\
\hline 2 & $\begin{array}{l}\text { Acute, } \\
\text { neuronopathic }\end{array}$ & $\begin{array}{l}\text { Severe neurological involvement } \\
\text { (supranuclear gaze palsy, strabismus, } \\
\text { opisthonus) } \\
\text { Lung involvement }\end{array}$ & None & Neonatal-infantile & $\begin{array}{l}\text { Poor (neonatal or } \\
\text { infantile demise) }\end{array}$ & Supportive \\
\hline 3 & $\begin{array}{l}\text { Subacute- } \\
\text { chronic, } \\
\text { neuronopathic }\end{array}$ & $\begin{array}{l}\text { Progressive neurologic involvement } \\
\text { and cognitive deterioration } \\
\text { (myoclonic seizures, supranuclear } \\
\text { gaze palsy) } \\
\text { Variable visceral involvement }\end{array}$ & $\begin{array}{l}\text { L444P, D409H } \\
\text { mutations } \\
\text { Arab and } \\
\text { Japanese } \\
\text { populations }\end{array}$ & $\begin{array}{l}\text { Variable (childhood- } \\
\text { adulthood) }\end{array}$ & $\begin{array}{l}\text { Shortened, variable } \\
\text { (childhood-early/mid- } \\
\text { adulthood) }\end{array}$ & $\begin{array}{l}\text { ERT for visceral } \\
\text { involvement }\end{array}$ \\
\hline
\end{tabular}


Table $\mathbf{2}$ Laboratory investigations in Gaucher disease

\begin{tabular}{|c|c|c|c|}
\hline Laboratory investigation & Basis & Advantages & Disadvantages \\
\hline Angiotensin-converting enzyme & $\begin{array}{l}\text { Increased in the plasma of } \\
\text { affected patients }\end{array}$ & Decreases with treatment & Nonspecific \\
\hline $\begin{array}{l}\text { Beta-glucocerebrosidase } \\
\text { activity assay }\end{array}$ & $\begin{array}{l}\text { Direct assessment of enzyme } \\
\text { responsible for disease }\end{array}$ & $\begin{array}{l}\text { Gold standard test } \\
\text { Elevated in active disease }\end{array}$ & Expense \\
\hline Bone marrow aspirate & $\begin{array}{l}\text { Visualization of Gaucher cells } \\
\text { in marrow }\end{array}$ & $\begin{array}{l}\text { Identification of alternative } \\
\text { or concomitant disease } \\
\text { entities with similar } \\
\text { presentations (e.g., } \\
\text { hematologic malignancy) }\end{array}$ & $\begin{array}{l}\text { Not routinely recommended if } \\
\text { Gaucher diagnosis is highly } \\
\text { suspected } \\
\text { Nonspecific (pseudo-Gaucher cells) } \\
\text { Discomfort } \\
\text { Expense }\end{array}$ \\
\hline CCL18 & $\begin{array}{l}\text { Produced by Gaucher cells as } \\
\text { macrophage chemokine }\end{array}$ & $\begin{array}{l}\text { Elevated in active disease } \\
\text { Suitable in chitotriosidase } \\
\text { deficient individuals } \\
\text { More closely reflects organ } \\
\text { volumes than chitotriosidase }\end{array}$ & $\begin{array}{l}\text { Expense } \\
\text { No head-to-head comparison } \\
\text { with chitotriosidase }\end{array}$ \\
\hline Chitotriosidase & $\begin{array}{l}\text { Released by glucocerebrosidase- } \\
\text { laden Gaucher cells }\end{array}$ & $\begin{array}{l}\text { Elevated in active disease } \\
\text { Reduction from baseline } \\
\text { values indicates treatment } \\
\text { response } \\
\text { Increasing values are consistent } \\
\text { with active disease }\end{array}$ & $\begin{array}{l}\text { Normal individuals occasionally } \\
\text { may not produce chitotriosidase } \\
\text { Can vary widely between patients } \\
\text { Expense }\end{array}$ \\
\hline DNA sequencing & $\begin{array}{l}\text { Testing for genetic mutations } \\
\text { (known and de novo) in the } \\
\text { GBA gene }\end{array}$ & $\begin{array}{l}\text { Provides detailed information } \\
\text { regarding genotype, which may } \\
\text { be associated with specific forms } \\
\text { of the disease } \\
\text { Identifies carriers }\end{array}$ & $\begin{array}{l}\text { Expense } \\
\text { Variable phenotypic expression }\end{array}$ \\
\hline $\begin{array}{l}\text { Ferritin, serum iron, iron } \\
\text { binding capacity }\end{array}$ & $\begin{array}{l}\text { Iron overload occurs in patients. } \\
\text { Uncertain etiology with possible } \\
\text { association with HFE gene } \\
\text { mutations, chronic inflammation }\end{array}$ & $\begin{array}{l}\text { Correlates with hepatomegaly } \\
\text { Decreases with treatment }\end{array}$ & $\begin{array}{l}\text { Nonspecific with poor correlation } \\
\text { with organ iron deposition on } \\
\text { imaging and disease severity scoring }\end{array}$ \\
\hline Glucosylsphingosine & $\begin{array}{l}\text { Byproduct related to } \\
\text { glucosylceramide, reflecting } \\
\text { beta-glucocerebrosidase function }\end{array}$ & $\begin{array}{l}\text { Correlates with other markers of } \\
\text { disease activity, organomegaly, } \\
\text { platelet levels } \\
\text { Decreases with treatment }\end{array}$ & Expense, availability \\
\hline $\begin{array}{l}\text { Liver function tests (AST, } \\
\text { ALT, bilirubin, albumin, } \\
\text { total protein) }\end{array}$ & $\begin{array}{l}\text { Hepatic dysfunction related to } \\
\text { liver infiltration is common }\end{array}$ & $\begin{array}{l}\text { Provides assessment of active } \\
\text { hepatic involvement }\end{array}$ & $\begin{array}{l}\text { May be insensitive to early } \\
\text { hepatic involvement }\end{array}$ \\
\hline $\begin{array}{l}\text { Routine hematological tests } \\
\text { (hemoglobin, platelet count, } \\
\text { coagulation parameters) }\end{array}$ & $\begin{array}{l}\text { Anemia and thrombocytopenia } \\
\text { hallmark features of this disease }\end{array}$ & $\begin{array}{l}\text { Provides information regarding } \\
\text { hematologic involvement that may } \\
\text { prompt other treatment }\end{array}$ & $\begin{array}{l}\text { Nonspecific for overall } \\
\text { disease severity }\end{array}$ \\
\hline $\begin{array}{l}\text { Tartrate-resistant acid } \\
\text { phosphatase }\end{array}$ & $\begin{array}{l}\text { Marker of osteoclasts and } \\
\text { Gaucher cells }\end{array}$ & Decreases with treatment & Nonspecific \\
\hline
\end{tabular}

However, active bone disease, even if asymptomatic, and significant hepatosplenomegaly are considered indications for initiating ERT in asymptomatic children [18]. Therefore, monitoring of patients not currently on therapy with imaging is clearly important in guiding clinicians as to early disease involvement [18].

As some patients may respond poorly to particular therapies, imaging can be important to inform clinicians regarding changes in an individual patient's response to specific therapies to provide personalized therapy decisions. The management of treated individuals who are asymptomatic despite biomarker and imaging findings of Gaucher disease poses a unique challenge, leading some clinicians to propose a concept of minimal disease activity wherein some treated patients may have mild persistent abnormalities on imaging and laboratory investigations without clinically significant disease [19]. Moreover, the substantial financial burden incurred by these therapies with annual treatment costs ranging between 70,000 and 380,000 USD $[8,20]$ may also motivate the use of imaging assessment of treatment response in well-controlled patients to assist in verifying efficacy and safety of reduced dosing schedules or alternative strategies to reduce the overall cost of therapy.

\section{Imaging of Gaucher disease involvement}

Due to the reliance on ERT and SRT for the long-term management of patients with Gaucher disease, 
Table 3 Historic and available therapies for Gaucher disease

\begin{tabular}{|c|c|c|c|}
\hline Medication name & Therapy type & Advantages & Disadvantages \\
\hline $\begin{array}{l}\text { Alglucerase } \\
\text { (Ceredase, Genzyme corporation) }\end{array}$ & $\begin{array}{l}\text { Enzyme } \\
\text { replacement }\end{array}$ & $\begin{array}{l}\text { Earliest therapy with demonstrated } \\
\text { improvements in organ involvement, } \\
\text { biomarkers, bone pain. } \\
\text { Satisfactory safety profile }\end{array}$ & $\begin{array}{l}\text { No longer available } \\
\text { Derived from human placenta } \\
\text { Intravenous route } \\
\text { Cost } \\
\text { Does not cross blood-brain barrier } \\
\text { Allergic reactions }\end{array}$ \\
\hline $\begin{array}{l}\text { Imiglucerase } \\
\text { (Cerezyme, Genzyme corporation) }\end{array}$ & $\begin{array}{l}\text { Enzyme } \\
\text { replacement }\end{array}$ & $\begin{array}{l}\text { Replaced alglucerase with comparable } \\
\text { therapeutic response } \\
\text { Satisfactory safety profile }\end{array}$ & $\begin{array}{l}\text { Intravenous route } \\
\text { Cost } \\
\text { Does not cross blood-brain barrier } \\
\text { Allergic reactions }\end{array}$ \\
\hline $\begin{array}{l}\text { Velaglucerase alfa } \\
\text { (VPRIV, Shire Human } \\
\text { Genetics Therapies) }\end{array}$ & $\begin{array}{l}\text { Enzyme } \\
\text { replacement }\end{array}$ & $\begin{array}{l}\text { Fewer allergic reactions } \\
\text { Comparable therapeutic response } \\
\text { with imiglucerase }\end{array}$ & $\begin{array}{l}\text { Intravenous route } \\
\text { Cost } \\
\text { Does not cross blood-brain barrier }\end{array}$ \\
\hline $\begin{array}{l}\text { Taliglucerase alfa } \\
\text { (Elelyso, Pfizer Inc.) }\end{array}$ & $\begin{array}{l}\text { Enzyme } \\
\text { replacement }\end{array}$ & Easier manufacturing, lower cost & $\begin{array}{l}\text { Intravenous route } \\
\text { Does not cross blood-brain barrier } \\
\text { Less therapeutic response data }\end{array}$ \\
\hline Miglustat (Zavesca, Actelion) & $\begin{array}{l}\text { Substrate } \\
\text { reduction }\end{array}$ & $\begin{array}{l}\text { Oral route } \\
\text { Potential to cross blood-brain barrier }\end{array}$ & $\begin{array}{l}\text { Failed to achieve neurological } \\
\text { treatment response } \\
\text { High prevalence of side effects } \\
\text { Cost }\end{array}$ \\
\hline Eliglustat (Genzyme corporation) & $\begin{array}{l}\text { Substrate } \\
\text { reduction }\end{array}$ & $\begin{array}{l}\text { Oral route } \\
\text { Early clinical evidence of } \\
\text { treatment response }\end{array}$ & $\begin{array}{l}\text { Drug-drug interactions } \\
\text { CYP2D6 and CYP3A metabolism } \\
\text { considerations } \\
\text { Cardiotoxicity } \\
\text { Does not cross blood-brain barrier } \\
\text { Cost }\end{array}$ \\
\hline
\end{tabular}

non-invasive imaging methods are essential in ascertainment of response to therapy and detection of disease-related complications. Therefore, understanding the role of different imaging modalities in the context of disease processes is important to provide clinicians and radiologists with guidance in assessing disease severity and treatment response. General strengths and limitations of each imaging modality are summarized in Table 4 [18, 21-24].

\section{Hepatic and splenic involvement \\ Organomegaly and infiltration}

While the inciting pathophysiological mechanism of Gaucher disease, enzymatic deficiency with accumulation of glucocerebroside, has been elucidated, the extent to which substrate accumulation accounts for liver enlargement has been called into question [25]. Originally, visceromegaly was attributed to simple accumulation glucocerebroside in the reticuloendothelial system with buildup of this material within Gaucher cells in the spleen as well as Kupffer cells in the liver [25]. However, newer evidence suggests that pro-inflammatory and pro-infiltrative chemotaxis factors may also account for organ enlargement with Gaucher cells contributing only partially to enlarged liver and spleen volumes [25, 26]. Regardless, severe hepatic involvement generally corresponds with additional organ system manifestations. Hepatosplenomegaly is a hallmark of Gaucher disease and uniformly present beginning in childhood, and liver disease is a major contributor to Gaucher disease-related mortality [27]. As such, traditional imaging of disease severity has been based on hepatic and splenic visceral organ enlargement $[24,25,28]$.

Organ sizes are interpreted from a clinical standpoint in the context of volume relative to the expected volume based on body weight, expressed as multiples of normal (MN) [18]. While there are a variety of available calculations for normal liver and spleen volumes in the imaging literature incorporating age, sex, and body mass index, most Gaucher disease studies utilize a simple weightbased formula for these normative values (normal liver volume $(\mathrm{mL})=25 \mathrm{~mL} / \mathrm{kg} \times$ weight $(\mathrm{kg})$; normal spleen volume $(\mathrm{mL})=2 \mathrm{~mL} / \mathrm{kg} \times$ weight $(\mathrm{kg}))$ that should be consistently employed to avoid confusion across studies [29]. Treatment objectives often include specific targets such as liver volumes of less than 1-1.5 $\mathrm{MN}$ and spleen volumes of $<2-8 \mathrm{MN}[8,30]$.

Organ volumes may be calculated using a variety of methodologies with the simplest being a volumetric estimate from orthogonal dimensions on conventional ultrasound. Conventional ultrasound has the benefit of being non-invasive and relatively inexpensive; most notably, ultrasound may avoid the use of sedation in younger children [31, 32]. While the longitudinal axis measurements on US modestly correlate with CT-derived volumes, others note that sonographic-derived values differ significantly from true volumetric measurements (Fig. 1) obtained on cross-sectional imaging, namely CT and 
Table 4 Imaging modalities relevant to Gaucher disease

\begin{tabular}{llll}
\hline Imaging modality & Gaucher disease manifestations & Advantages & Limitations \\
\hline Magnetic resonance & Abdominal: organ & Offers both qualitative and & Expense \\
imaging without & enlargement, heterogeneous & quantitative multisystem & Contraindications in selected individuals \\
intravenous contrast & parenchymal signal, hepatic and & assessment including & Sedation requirement for certain patients
\end{tabular}

splenic lesions, decreased ADC in

affected organs

(n)

signal, avascular necrosis, fracture, Reproducible vertebral height loss

Quantitative chemicalshift imaging (QCSI), lumbar spine and proximal femurs

\section{Magnetic resonance} spectroscopy

Magnetic resonance elastography

Magnetic resonance imaging with hepatocyte-specific intravenous contrast

DXA

Computed tomography with intravenous contrast

Ultrasound, abdomen

\author{
Chest CT \\ 99 m-Tc-Sestamibi \\ scintigraphy
}

99 m-Tc-MDP scintigraphy
Abdominal and skeletal: decreased fat-fractions

Abdominal and skeletal: decreased fat-fractions

Abdominal: increased liver and spleen stiffness values

Abdominal: organ enlargement, heterogeneous parenchymal signal, hepatic and splenic lesions

Osteopenia consistent with worsening marrow infiltration

Accurate, reproducible Validated in several studies to correlate with biomarkers and respond to treatment

Accurate, reproducible More reliable at lower fatfractions than chemical-shift imaging

Non-invasive, no ionizing radiation

May be obtained in conjunction with other MRI evaluations

Gold-standard for liver lesion characterization

Non-invasive, no ionizing radiation

Reproducible

Osteopenia indicates worsening skeletal involvement and may predict pathologic fracture risk Nominal ionizing radiation exposure

Availability

Satisfactory identification

of lesions heterogeneous parenchymal attenuation, hepatic and splenic lesions

Abdominal: organ enlargement, heterogeneous hepatic echotexture, hepatic and splenic lesions
Accessible, affordable radiation equivalent to $\mathrm{C} T$ for screening for liver complications Non-invasive, no ionizing
Availability, technical expertise

Expense

Cannot be measured in areas of osteonecrosis or vertebral collapse

Limited validation

Availability, technical expertise

Expense

Acquisition time

Availability

Expense

Less well-validated

Expense

Contrast administration-related issues Low-yield in the absence of previously identified suspicious or indeterminate lesion May not avoid need for confirmatory biopsy in Gaucher disease to overlap between liver involvement and suspicious imaging features

Unreliable in sites of osteonecrosis and compression deformity

Normative values unreliable below 6 years of age

Low-yield in younger children at lower risk of fracture

Predictive value of BMD to predict fracture risk in children is undefined

Incomplete characterization of focal lesions lonizing radiation exposure

(may be optimized for dose reduction)

Operator dependent, protocols sometimes rely on single operator

Overlap of benign and malignant focal

lesion characteristics requiring additional workup

Less sensitive than MRI for comprehensive assessment of organ involvement

Disagreement with volumes obtained on other modalities

Pulmonary involvement is rare Findings often nonspecific lonizing radiation exposure

lonizing radiation exposure

Poor spatial resolution

Limited validation data

Low specificity

Not well-validated

lonizing radiation exposure

Availability

Expense

Poor spatial resolution

Not specific

Low-yield in pediatric population 
Table 4 Imaging modalities relevant to Gaucher disease (Continued)

\begin{tabular}{|c|c|c|c|}
\hline Imaging modality & Gaucher disease manifestations & Advantages & Limitations \\
\hline and cardiac MRI & $\begin{array}{l}\text { (mostly adults on treatment) } \\
\text { Valvular calcifications (D409H } \\
\text { homozygous mutation) }\end{array}$ & $\begin{array}{l}\text { radiation } \\
\text { Definitive investigations for } \\
\text { cardiac involvement }\end{array}$ & $\begin{array}{l}\text { Expense } \\
\text { Limited data to support widespread } \\
\text { use, particularly for cardiac MRI }\end{array}$ \\
\hline $\begin{array}{l}\text { Acoustic radiation } \\
\text { force impulse/shear } \\
\text { wave elastography (US) }\end{array}$ & $\begin{array}{l}\text { Increased liver and spleen } \\
\text { stiffness values }\end{array}$ & $\begin{array}{l}\text { Similar or higher performance } \\
\text { compared with transient elastography } \\
\text { Non-invasive, no ionizing radiation } \\
\text { May be combined with conventional } \\
\text { US evaluation of organ involvement } \\
\text { No sedation }\end{array}$ & $\begin{array}{l}\text { Availability } \\
\text { Measurement variability }\end{array}$ \\
\hline Transient elastography & $\begin{array}{l}\text { Increased liver and spleen } \\
\text { stiffness values }\end{array}$ & $\begin{array}{l}\text { Non-invasive, no ionizing radiation } \\
\text { Expense }\end{array}$ & $\begin{array}{l}\text { No imaging guidance to assess most } \\
\text { affected regions of organs } \\
\text { No imaging component for further } \\
\text { characterization of organ parenchyma } \\
\text { quality or lesions }\end{array}$ \\
\hline
\end{tabular}

MRI, and ultrasound may also depend on a single reader over serial evaluations for consistency [31, 33, 34]. Therefore, many consensus recommendations caution against the use of ultrasound [18]. In more recent years, there is widespread agreement upholding the use volumetric MRI over CT, given concerns regarding ionizing radiation exposure from repeated examinations, and additional information obtainable with MRI [24]. Semi-automated techniques of measuring organ volumes on MRI also afford more reliable measurements and avoid dependence on specialized readers [35].

Organ volumes decrease substantially with therapy initiation, although some have noted that well-controlled disease may result in plateauing of organ volumes after the first 3 years of successful treatment [34].

Diffusion-weighted imaging (DWI) offers another quantitative assessment of organ infiltration as a surrogate of tissue cellularity [36]. Apparent diffusion coefficient $(\mathrm{ADC})$ values in the liver and spleen appear to

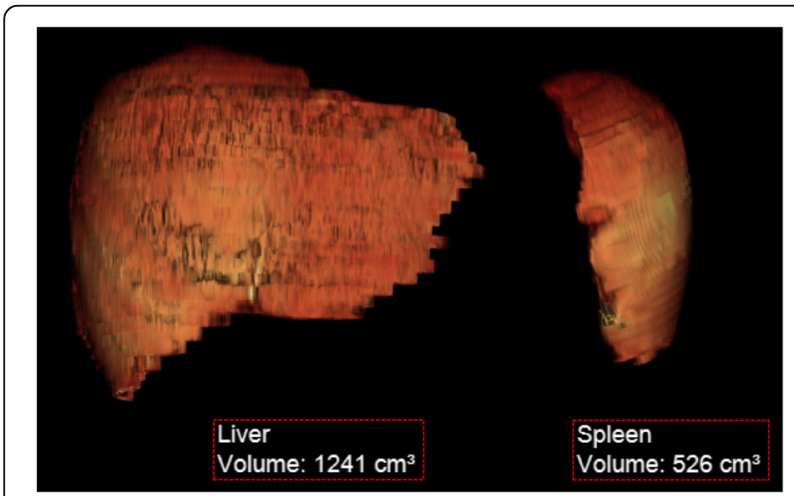

Fig. 1 Three-dimensional reconstructions of liver and spleen volumes from MRI in Gaucher disease. Volume-rendered organ volume reconstructions generated from non-contrast MRI data were used to track treatment response in a 9-year-old male with Gaucher disease. Organ volumes for the liver (1241 mL, 1.03 MN) and spleen ( $526 \mathrm{~mL}, 5.44 \mathrm{MN}$ ) are decreased from a prior examination at 6 years of age (1.35 MN and $6.43 \mathrm{MN}$, respectively) correlate well with chitotriosidase as a marker of disease severity in one pediatric study with decreased ADC connoting greater infiltration and worse involvement [37].

\section{Liver fibrosis}

While cirrhosis and portal hypertension have been traditionally regarded as rare in Gaucher disease [38], there is increased risk for liver fibrosis, cirrhosis, and hepatocellular carcinoma (HCC) in this condition, especially in previously splenectomized individuals [39-41]. Gaucher cell deposition may establish a fibrogenic microenvironment due to chronic low-grade inflammation [25, 27]. In Gaucher disease, liver fibrosis is thought to increase the increased risk of hepatic cirrhosis, HCC risk, and liver disease-related mortality.

Advances in the understanding of Gaucher disease and observations of elevated ferritin levels and increased risk of hepatic fibrosis suggest greater importance of imaging assessment for complications of liver involvement beyond simple organ enlargement. Ultrasound has been traditionally used to monitor development of cirrhotic morphology (Fig. 2) but is relatively insensitive in detecting earlier fibrotic changes. Some means of noninvasively assessing hepatic fibrosis include non-imaging-based transient elastography (TE), ultrasound shear wave elastography (SWE), and magnetic resonance elastography (MRE) [42]. These elastography modalities provide reliable measurements that can detect significant liver fibrosis each with unique strengths and limitations summarized in Table 4 [42].

Liver stiffness may be only mildly elevated in Gaucher disease patients without cirrhosis, likely reflecting treatment-related reductions in the extent of liver fibrosis [43]. However, Gaucher disease patients with cirrhosis exhibit markedly elevated liver stiffness values [43], and other studies of patients who were previously splenectomized (with more severe disease) demonstrated greater liver stiffness compared with patients with milder disease $[40,44]$. In a recent study, MRE-measured liver 


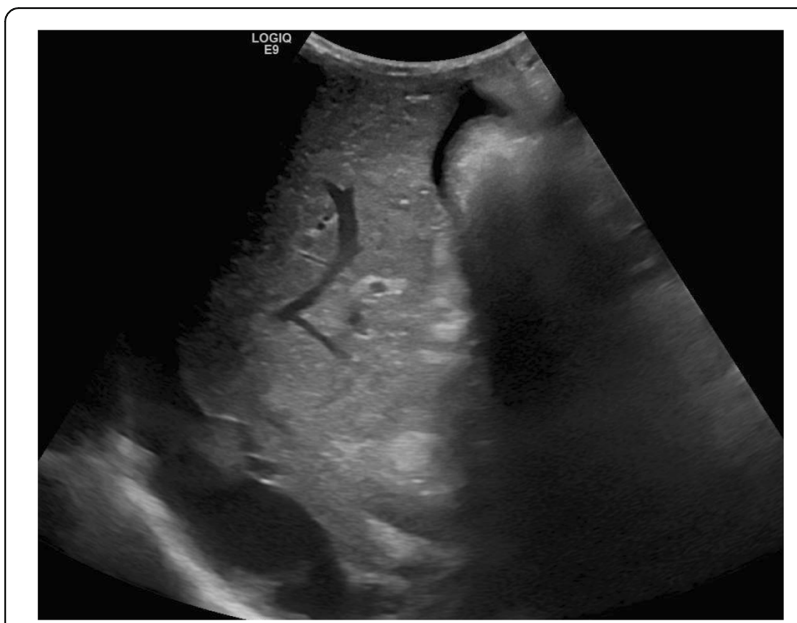

Fig. 2 Liver cirrhosis in pediatric Gaucher disease. Sagittal grayscale ultrasound demonstrates an enlarged liver with nodular cirrhotic morphology and perihepatic ascites in a 12-year-old male with Gaucher disease

stiffness values correlated with Gaucher clinical severity (GD-DS3) scores, highlighting the potential clinical utility of evaluating liver stiffness in this disease [44]. These findings suggest a role for elastography-based modalities in identifying early hepatic fibrosis in Gaucher disease patients, although further study is needed to better understand the extent of fibrosis in Gaucher disease and the clinical utility of earlier identification.

\section{Iron overload}

Other important clinical manifestations of Gaucher disease include hematologic abnormalities such as anemia and hyperferritinemia. The precise etiology of hyperferritinemia in Gaucher disease is poorly understood, although it is a frequent finding that may correspond with other indicators of disease severity and respond to ERT $[45,46]$. Ferritin levels are also noted to be higher in asplenic patients, a finding that may be confounded by greater disease severity in these patients also often requiring blood transfusions [45]. From an imaging standpoint, hyperferritinemia with iron deposition such as within the liver may appear on with increased attenuation on CT, signal drop-out on out-of-phase gradient T1-weighted MRI and low signal on T2*-weighted MRI [47]. A group of investigators highlighted substantial iron deposition (as indicated by $\mathrm{R}^{*}$ values) in treated Gaucher disease patients compared with controls [48]. However, the precise relationship between hyperferritinemia and visceral iron deposition is poorly understood in Gaucher disease and the subject of continued investigation.

\section{Liver lesions}

The majority of liver lesions encountered in Gaucher disease are thought to be related to focal deposition of glucocerebroside within the Kupffer cells [39]; however, Gaucher disease confers substantial increased risk of malignancy and HCC $[49,50]$.

In one large ultrasound study of Gaucher disease patients, focal liver lesions were identified in just under $5 \%$ of individuals; the majority of which were multiple hyperechoic lesions [39]. Authors have suggested that such small, hyperechoic lesions do not merit biopsy if slowly growing, as they are thought to reflect focal accumulation of Gaucher cells [39]. On the other hand, early studies of MRI in Gaucher disease identified focal signal abnormalities in about one-fifth of patients [51]. Such focal accumulations of Gaucher cells are thought to be hypoattenuating on CT, hypointense on T1-weighted imaging, and heterogeneous on T2-weighted imaging (Fig. 3).

In addition, reports of biopsy-proven hepatic amyloidosis have been made in rare numbers of patients $[39,52,53]$. More worrisome, $\mathrm{HCC}$ can develop at younger ages in Gaucher disease; the previously mentioned large series
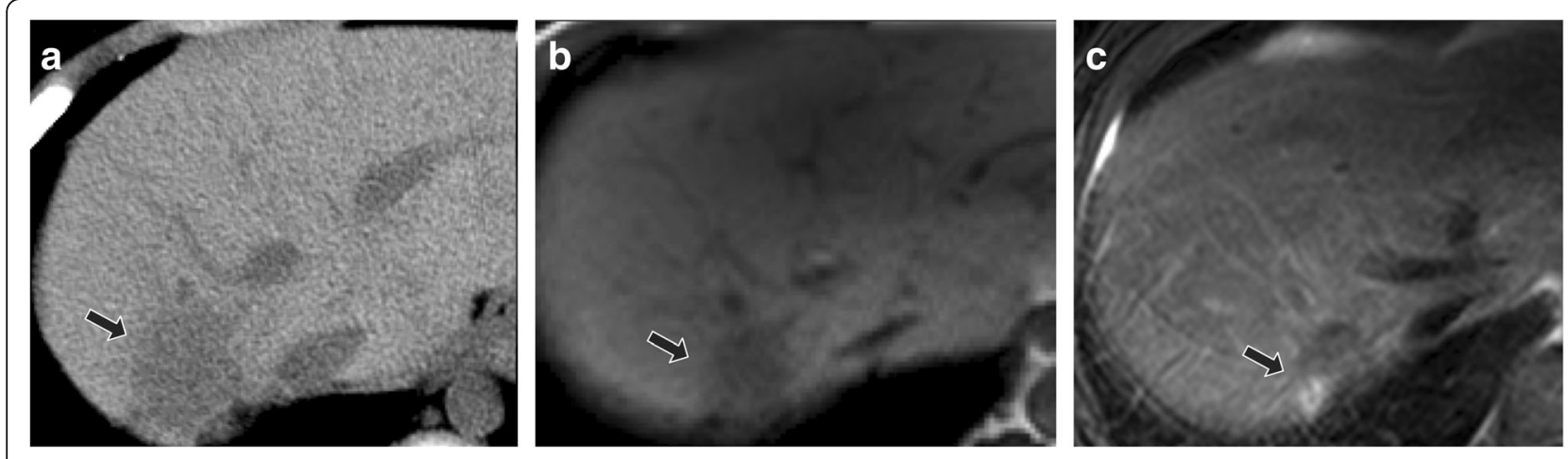

Fig. 3 Focal Gaucher cell accumulation in the liver. Axial non-contrast abdominal CT (a) demonstrates a focal hypoattenuating hepatic lesion (arrow) in the posterior right hepatic lobe in 10-year-old male with type 1 Gaucher disease. At follow-up at 16 years of age with unenhanced MRI, lesion (arrow) was unchanged in size with T1-weighted hypointense (b) and mixed T2-weighted signal intensity (c). Findings are most consistent with focal Gaucher cell deposition ("Gaucheroma") 
identified only one case of $\mathrm{HCC}$, which was found in the setting of rapidly progressive cirrhotic morphology on serial US evaluations [39].

Therefore, screening evaluation for development of suspicious liver lesions is warranted in Gaucher disease. Identification of more suspicious (e.g., hypoechoic, large, irregular, hypervascular) lesions may warrant further investigation with dedicated liver protocol CT, hepatocytespecific contrast-enhanced MRI, or contrast-enhanced US, which may offer a viable alternative especially for children [54].

\section{Spleen fibrosis}

Gaucher patients also demonstrate significantly elevated spleen stiffness values using a variety of elastography techniques [43]. Elevated stiffness values observed in Gaucher disease (Fig. 4) may reflect progressive infiltration and inflammatory changes culminating in fibrosis. Elevated spleen stiffness has been deemed a harbinger of portal hypertension in non-Gaucher disease conditions [42]; however, prospective assessment of the clinical significance of splenic fibrosis in Gaucher disease is needed.

\section{Splenic lesions}

Similar to the previously described hepatic lesions thought to represent focal Gaucher cell buildup, patients with Gaucher disease are often noted to have hyperechoic splenic lesions on ultrasound in one-fifth to one-third of cases [43]. These lesions tend to be low in attenuation with occasional peripheral calcification on CT [55]. On MRI, Gaucher-related splenic nodules usually demonstrate low T1-weighted and high T2-weighted signal intensity, although focal areas of necrosis are also

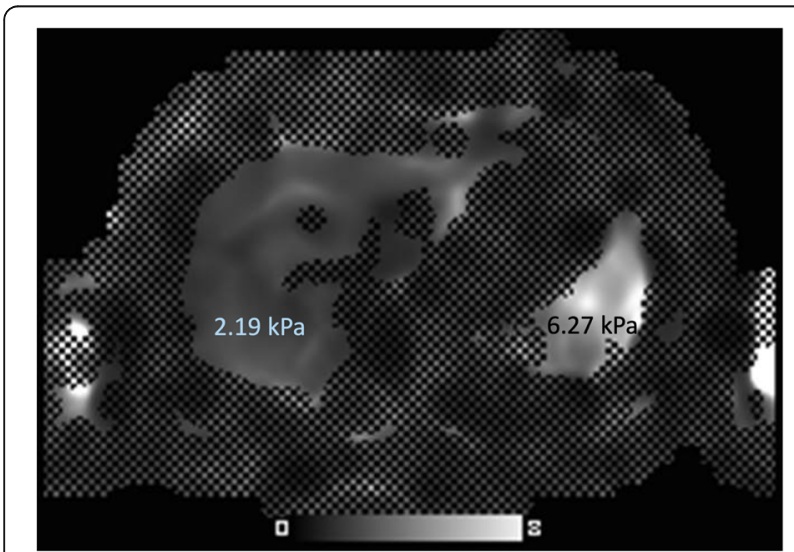

Fig. 4 Spleen fibrosis in pediatric Gaucher disease. Axial MR elastography of a 13-year-old patient with newly diagnosed, untreated type 1 Gaucher disease demonstrates elevated spleen stiffness values (6.27 kPa, abnormal defined greater than $3.6 \mathrm{kPa}$ ), but no significant hepatic fibrosis identified $(2.19 \mathrm{kPa}$, abnormal defined greater than $2.9 \mathrm{kPa}$ ) encountered which can be hypointense on T1-weighted imaging [32, 55]. Early MRI studies demonstrated that numbers of splenic nodules correlated with spleen size; these investigators posited that these lesions often represent areas of infarction in the setting of splenic infiltration [56]. These splenic nodules appear to be more common in adults, likely reflecting longstanding infiltration needed to result in ischemia [51]. Similarly, subcapsular splenic infarcts were commonly noted as well prior to introduction of effective ERT [51]. In especially severe cases, splenic necrosis may occur with replacement with fluid attenuation material and peripheral calcification (Fig. 5).

\section{Skeletal involvement and complications}

In patients with type 1 Gaucher disease, bone marrow involvement represents a spectrum of disease (Fig. 6) with some level of involvement in nearly every patient $[4,57,58]$. Recognition that musculoskeletal manifestations may be the presenting symptom of Gaucher disease is important to avoid confusion with other conditions with overlapping symptoms and signs such as hematopoietic malignancies and rheumatologic conditions [59]. Infiltration of the bone marrow with Gaucher cells with concomitant osteopenia progressively compromises the bone density of the axial then appendicular skeleton with prominent lower extremity involvement of the proximal femurs and tibias [22, 60, 61]. Upper extremity involvement, while less commonly recognized, is also a substantial contributor to musculoskeletal morbidity with many children and adolescents reporting upper extremity pain.

Greater severity of musculoskeletal involvement often corresponds with severe organ involvement. Early investigations of bone involvement in Gaucher disease believed bone changes were irreversible [56]. However, newer studies have shown that treatment results in substantial improvement of early bone marrow changes in many patients. The prognosis of skeletal involvement once complications have occurred remains poor and bone marrow responses take longer than organ responses [55, 62]. Bone turnover biomarkers have largely failed to risk stratify patients, making imaging evaluation of musculoskeletal involvement indispensable to clinical management [57].

\section{Marrow infiltration}

Abnormal bone marrow involvement in Gaucher disease is a prominent finding, almost uniformly noted in type 1 patients and most conspicuously involves the spine, femurs, tibias, and humeri. Anemia commonly encountered in this condition results in greater hematopoietic marrow than expected for age, and direct accumulation of Gaucher cells also contributes to abnormal bone 

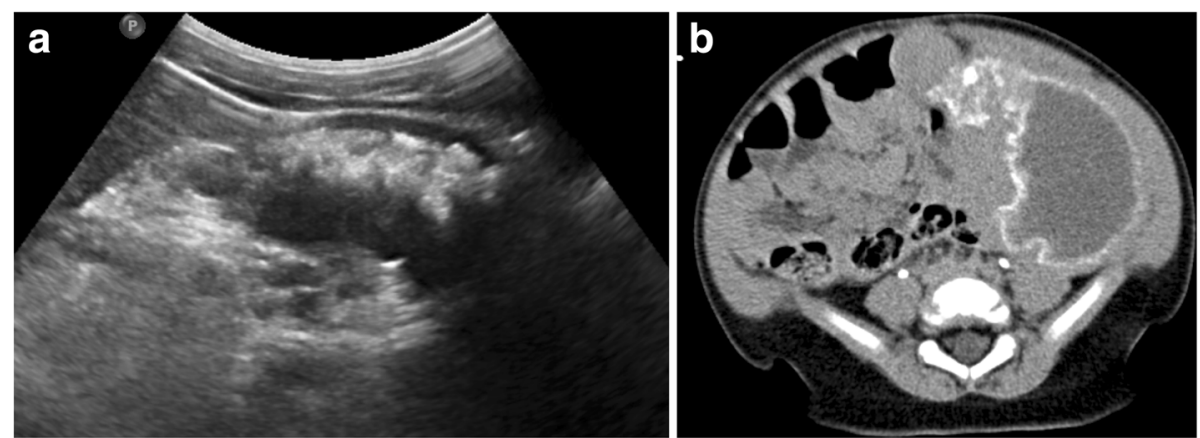

Fig. 5 Splenic necrosis in pediatric Gaucher disease. Transverse grayscale abdominal ultrasound (a) of a 2-year-old male Gaucher disease patient with marked splenomegaly shows replacement of normal splenic parenchyma with fluid and hyperechoic regions corresponding to dystrophic calcification. Contrast-enhanced abdominal CT (b) of this patient demonstrates enlarged spleen replaced with liquefying necrosis and peripheral dystrophic calcifications

marrow. Marrow involvement follows a pattern of centrifugal spread with the epiphyses and apophyses mostly spared except in the most severe of marrow infiltration [61]. Bone marrow involvement has long been regarded as more difficult to treat than visceral involvement. A previous study showed through histological examinations a decreased uptake of administered alglucerase within the bone marrow [63]. Marrow infiltration of the lumbar spine is thought to be more responsive to therapy, whereas some authors regard femoral marrow reflecting more static disease [64].

Subjective imaging assessment Radiographs are insensitive for detection of marrow infiltration; substantial medullary cavity expansion is needed to result in the classically reported Erlenmeyer flask deformity of the distal femur (Fig. 7) [22, 65]. In addition, the Erlenmeyer

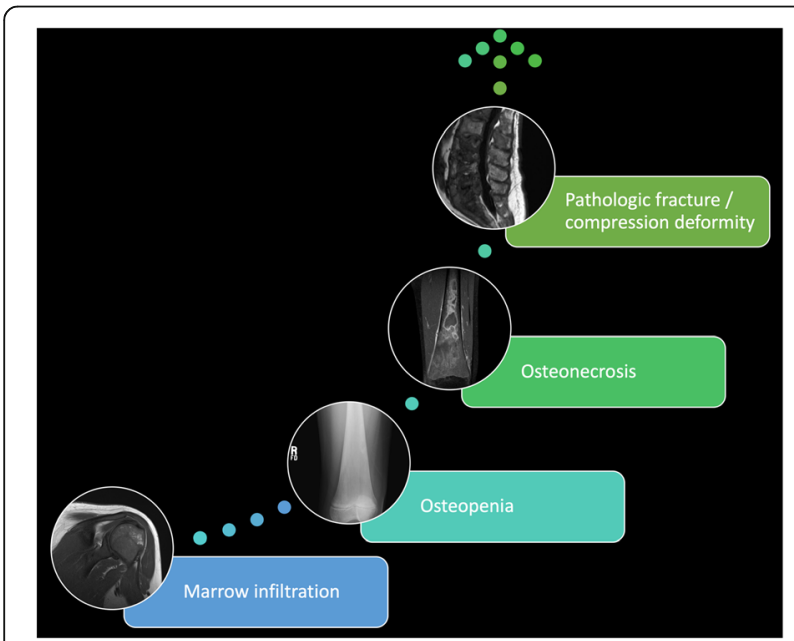

Fig. 6 Spectrum of musculoskeletal involvement in Gaucher disease. Nearly all type 1 Gaucher disease patients experience musculoskeletal manifestations ranging from marrow infiltration and osteopenia to pathologic fractures and compression deformities of the spine flask finding is nonspecific for Gaucher disease, being encountered in a variety of other conditions reviewed at-length elsewhere [66]. Initial marrow infiltration can be patchy, also making radiographic detection impossible [67].

Marrow infiltration manifests with low signal on T1-weighted imaging (Fig. 8). Early qualitative MRI assessments of marrow involvement in patients on ERT-based noted T1-weighted signal increases corresponded with reduced organ volumes with changes observed as early as 1 year $[46,62]$. This increase in T1-weighted signal is thought to reflect greater accumulation of yellow marrow with decreased concentration of Gaucher cells and hematopoietic marrow. Interpretation of qualitative marrow changes in children should be interpreted within the context of developmental changes in hematopoietic marrow $[10,68]$.

Semi-quantitative imaging assessment Numerous semi-quantitative scoring methods have been developed to report overall extent of bone marrow involvement based on signal intensity alterations on MRI, each with specific objectives and limitations summarized in Table 5 [61, 69]. Semi-quantitative region-of-interest (ROI)-based techniques have been offered up as slightly more objective alternatives to signal intensity based methods; the most commonly performed of these methods is the vertebra disc ratio (VDR) in which ROIs are placed on T1-weighted images of the lumbar spine $[70,71]$. Out of these methods, the bone marrow burden (BMB) score (Table 6) based on conventional lumbar spine and femur MRI is the most validated and correlates well with disease severity, splenectomy status (indicative of more severe disease), treatment response, and quantitative fat fractions [20, 23, 64, 72-75]. Another method, the Spanish-MRI (S-MRI) score, also incorporates imaging of the pelvis [76]. More recent investigations have applied some of these semi-quantitative 


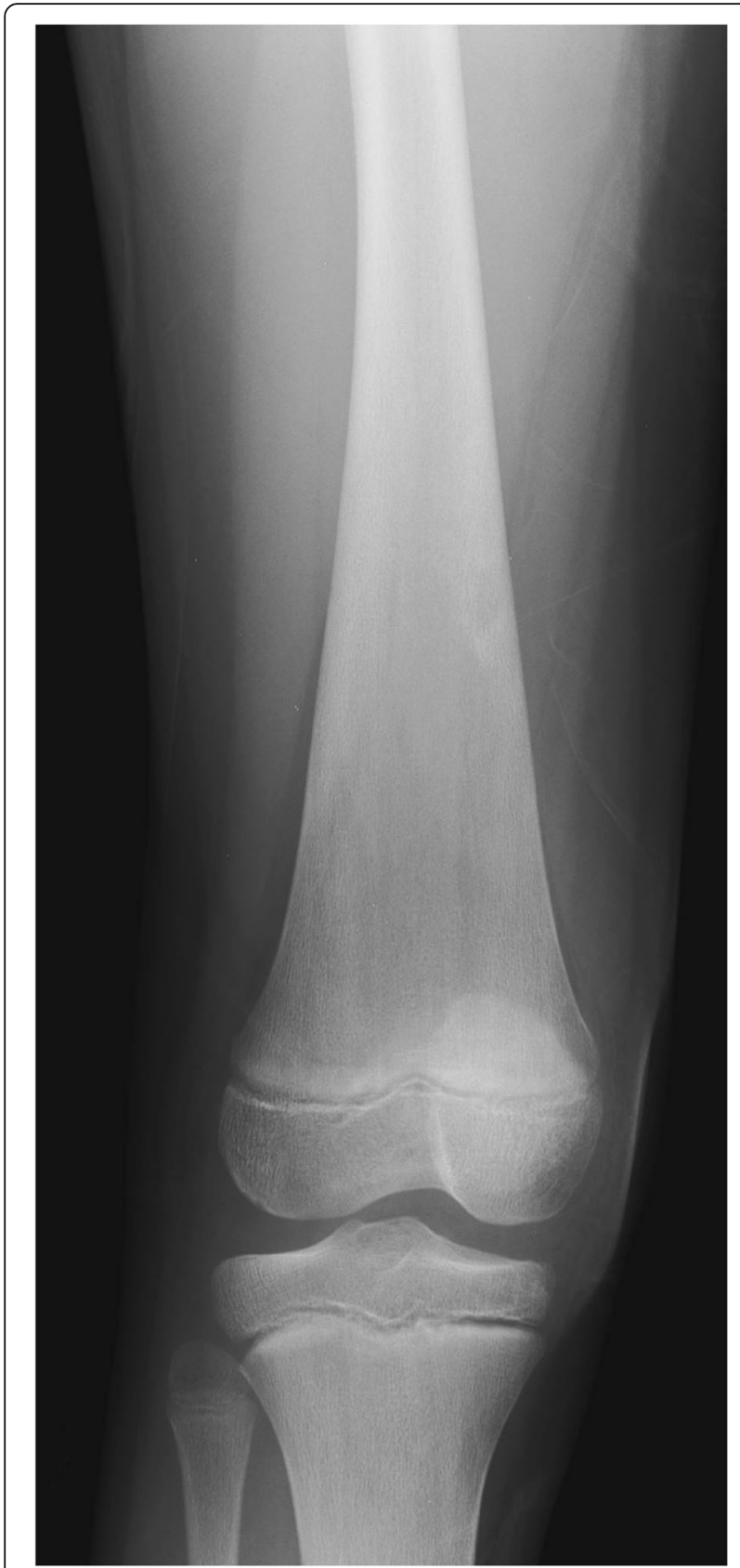

Fig. 7 Erlenmeyer flask deformity. Frontal radiograph of the right knee in a 12-year-old-male Gaucher disease patient with widening of the distal femoral diaphysis and metaphysis resulting in Erlenmeyer flask deformity

scoring techniques to whole-body MRI to assess treatment response [77-79]. While the reliability of these measures is promoted by several small studies, more recent work has called reliability of $\mathrm{BMB}$ scoring into question with poor interobserver agreement and others have pointed out issues related to later fat marrow conversion in children [77, 80].

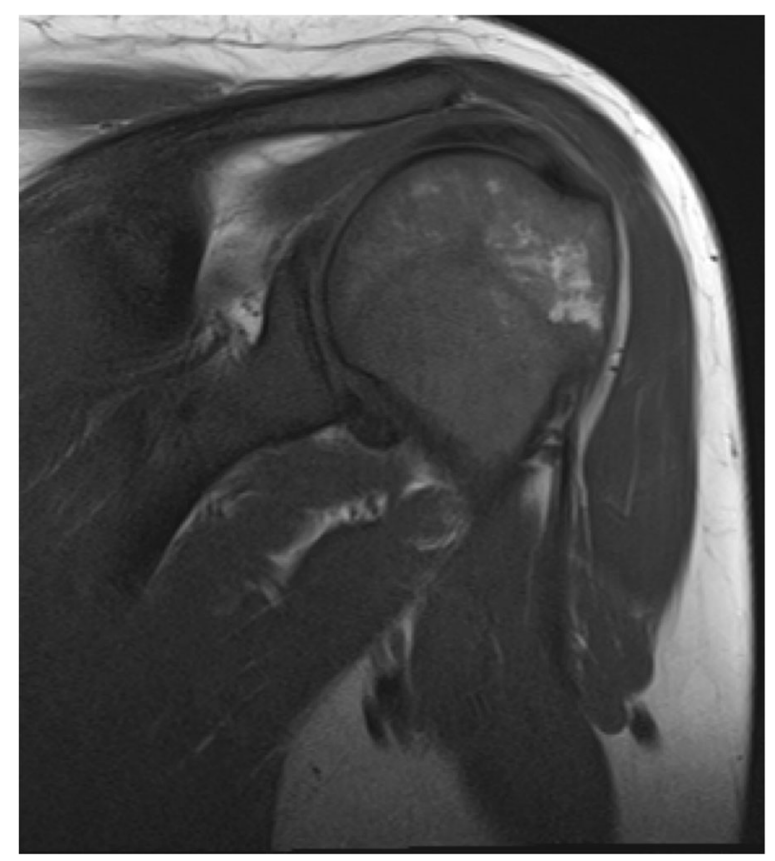

Fig. 8 Marrow infiltration in Gaucher disease. A 30-year-old female with type 1 Gaucher disease with shoulder pain. Coronal T1-weighted imaging demonstrates diffuse hypointense infiltration of the humerus including the proximal epiphysis compared to subcutaneous fat

Quantitative imaging assessment Multiple quantitative factors have been proposed to objectively assess marrow involvement in Gaucher disease and are supported by histopathologic evidence of an inverse relationship between marrow glucocerebroside and triglyceride concentrations [72]. Some of earliest quantitative assessments of bone marrow composition were performed using dual-energy CT and noted low amounts of marrow fat in patients [81, 82]. These initial investigations envisioned fat fractions as a marker of bone marrow disease severity with lower values representing greater infiltration [81]. Early MRI investigations noted longer T1 relaxation times in the bone marrow as well as decreases in these values with treatment $[83,84]$. The emergence of MRI techniques shortly following these $\mathrm{CT}$ investigations led to the abandonment of CT for this indication, and fat fractions calculated from MRI have become the dominant quantitative variable to report marrow involvement [61, 84].

Currently, quantitative MRI-based fat fraction measurements have been applied to objectively assess marrow involvement in Gaucher disease. Quantitative chemical-shift imaging (QCSI) using Dixon-based techniques and MRS are both capable of reliably measuring bone marrow fat fraction [85-90]. Work by Maas and colleagues has suggested a cut-off of 0.23 for a fat fraction ratio-values lower than this suggest a markedly elevated risk of bone-related complications [91]. Early studies also identified a correlation between marrow fat 
Table 5 Semi-quantitative Gaucher disease bone marrow involvement scoring systems

\begin{tabular}{|c|c|c|c|c|c|c|}
\hline Classification & $\begin{array}{l}\text { Bone marrow } \\
\text { burden (BMB) }\end{array}$ & $\begin{array}{l}\text { Spanish MRI } \\
\text { (S-MRI) }\end{array}$ & Terk & Rosenthal staging & $\begin{array}{l}\text { Duseldorf bone } \\
\text { marrow disease } \\
\text { score }\end{array}$ & $\begin{array}{l}\text { Vertebra-disc } \\
\text { ratio }\end{array}$ \\
\hline Sites & $\begin{array}{l}\text { Femurs } \\
\text { Lumbar spine }\end{array}$ & $\begin{array}{l}\text { Femurs } \\
\text { Lumbar spine } \\
\text { Pelvis }\end{array}$ & Femurs & Lower extremities & $\begin{array}{l}\text { Lower } \\
\text { extremities }\end{array}$ & Lumbar spine \\
\hline Considerations & $\begin{array}{l}\text { Most validated method } \\
\text { Correlates with } \\
\text { quantitative } \\
\text { Modified method allows } \\
\text { use of STIR acquisition } \\
\text { Confusion with red marrow } \\
\text { in younger patients }\end{array}$ & $\begin{array}{l}\text { Less validated } \\
\text { Relevance of } \\
\text { pelvis imaging } \\
\text { is questioned } \\
\text { Confusion with } \\
\text { red marrow in } \\
\text { younger patients }\end{array}$ & $\begin{array}{l}\text { Does not appreciate } \\
\text { more reversible changes } \\
\text { seen within the axial } \\
\text { skeleton } \\
\text { Confusion with } \\
\text { red marrow in } \\
\text { younger patients }\end{array}$ & $\begin{array}{l}\text { Less sensitive than } \\
\text { methods including } \\
\text { lumbar involvement } \\
\text { Confusion with } \\
\text { red marrow in } \\
\text { younger patients }\end{array}$ & $\begin{array}{l}\text { Correlates with } \\
\text { severe disease } \\
\text { Less sensitive } \\
\text { than methods } \\
\text { including } \\
\text { lumbar spine }\end{array}$ & $\begin{array}{l}\text { Quantitative } \\
\text { region-of- } \\
\text { interest based } \\
\text { measurement } \\
\text { Limited clinical } \\
\text { validation data }\end{array}$ \\
\hline
\end{tabular}

fractions and spleen size, suggesting an association between bone marrow and visceral disease severity [84]. One small MRS study noted significantly lower fat fractions in the proximal femurs but not the lumbar spine of mostly asymptomatic children with Gaucher children compared with age-matched controls [92]. Treatmentrelated responses in bone marrow fat fractions have been demonstrated in response to ERT (Fig. 9) [93-95]. A fat fraction of 0.37 (derived from normal controls) or more is proposed as a reference goal for treatment response [72]. Marrow fat quantification may serve as a means of prognostication and identifying nonresponders with responses noted as early as 1 year [91, 93, 95].

The importance of understanding developmental increases in marrow fat over the lifespan beginning first in the peripheral skeleton as well as normal variation in bone marrow fat fractions cannot be understated.
Patient age, sex, and body mass index should be considered in the interpretation of these values, ideally in the context of normative data relevant to the measurement method [88, 96-98]. Importantly, untreated Gaucher patients do not seem to exhibit normal expected age-related increases in fat fractions [93]. Adoption of QCSI for fat fraction measurements has been stymied for decades outside a few selected academic medical centers due to technical requirements, but the recent release of commercially available sequences may lead to a revival of fat fraction quantification $[88,99]$.

DWI may also hold promise with some evidence of decreased vertebral marrow ADC reflecting increased cellularity corresponding with disease status [100]. Last, iron filtration in marrow has been quantified in Gaucher disease with elevated $\mathrm{R} 2 \%$ values in femoral and vertebral marrow compared to matched healthy controls [48].

Table 6 Bone marrow burden (BMB) classification

\begin{tabular}{|c|c|c|c|c|}
\hline & Femurs & & Lumbar spine & \\
\hline \multirow[t]{4}{*}{ Involvement } & Site & Score & Site & Score \\
\hline & Diaphysis & 1 & Patchy & 1 \\
\hline & Proximal epiphysis/apophysis & 2 & Diffuse & 2 \\
\hline & Distal epiphysis & 3 & Absence of fat in basiverteral region & 1 \\
\hline Sequence & Signal intensity ${ }^{a}$ & Score & Signal intensity ${ }^{\mathrm{b}}$ & Score \\
\hline \multirow[t]{6}{*}{$\mathrm{T}_{2}$-weighted, (or, STIR) $)^{\mathrm{c}}$} & Hyperintense & $2(2)$ & Hyperintense & $2(2)$ \\
\hline & Slightly hyperintense & $1(1)$ & Slightly hyperintense & $1(1)$ \\
\hline & Isointense & $0(0)$ & Isointense & $0(0)$ \\
\hline & Slightly hypointense & $1(\mathrm{~N} / \mathrm{A})$ & Slightly hypointense & $1(\mathrm{~N} / \mathrm{A})$ \\
\hline & Hypointense & $2(\mathrm{~N} / \mathrm{A})$ & Hypointense & $2(\mathrm{~N} / \mathrm{A})$ \\
\hline & Mixed type & $3(3)$ & & \\
\hline \multirow[t]{5}{*}{$\mathrm{T}_{1}$-weighted } & Slightly hyperintense or isointense & 0 & Slightly hyperintense & 0 \\
\hline & Slightly hypointense & 1 & Isointense & 1 \\
\hline & Hypointense & 2 & Slightly hypointense & 2 \\
\hline & & & Hypointense & 3 \\
\hline & & Sum & & Sum \\
\hline
\end{tabular}

${ }^{\mathrm{a}}$ Relative to subcutaneous fat

${ }^{b}$ Relative to normal intervertebral disc

${ }^{c}$ Modified BMB scoring with STIR instead of $\mathrm{T}_{2}$-weighted imaging, adjusted scoring indicated in parentheses 


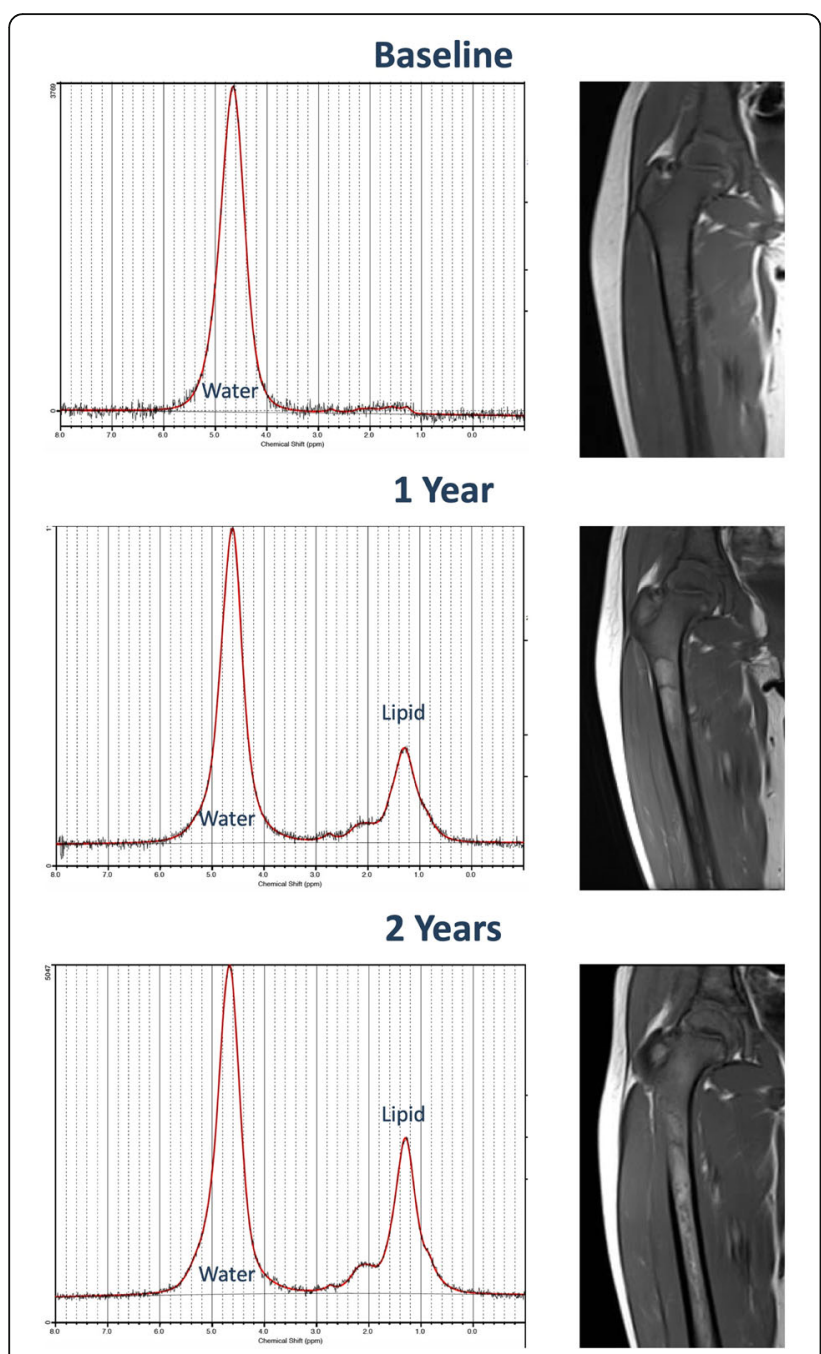

Fig. 9 Magnetic resonance spectroscopy assessment of marrow response to treatment. Gaucher disease patient with first imaging at 15 years of age subsequently treated with ERT. Magnetic resonance spectroscopy spectra (left) show increasing fat-fraction on follow-up examinations. Conventional T1-weighted coronal images (right) of the right femur demonstrate diffuse marrow infiltration with subtle fat infiltration with time

Metabolic imaging assessment Nuclear medicine studies are not routinely used for routine follow-up assessment of Gaucher disease at most institutions, although $99 \mathrm{~m}$-Tc-Sestamibi scintigraphy has been studied as an alternative means of quantifying bone marrow involvement with good agreement with MRI-based semi-quantitative scoring [101, 102]. Treatment-related changes have been successfully observed using 99 m-Tc-Sestamibi scintigraphy [103]. Other scintigraphy methods are largely ineffective at quantifying marrow involvement as typical bone radiotracers are only taken up by normal marrow, but $99 \mathrm{~m}$-Tc-MDP could potentially be helpful in discerning between bone crises and osteomyelitis, although this observation is not well validated
[22]. Nuclear medicine-based techniques are hampered by limited spatial resolution and inherent ionizing radiation exposure. While sestamibi patterns do not appear to be affected by age-related marrow conversion, ionizing radiation exposure incumbent in this technique precludes adoption for pediatric imaging [32]. In the future, targeted assessment of disease involvement may be possible with promising experimental positron emission tomography data using a 18F-labeled glucocerebrosidase [104]. In current practice, superior assessment of both marrow, osseous complications, and soft tissues has made MRI the modality of choice for the evaluation of musculoskeletal manifestations of Gaucher disease.

\section{Osteopenia}

One of the earliest skeletal manifestations of Gaucher disease type 1 in children is osteopenia [31]. The development of osteopenia in Gaucher disease is multifactorial with abnormal osteoclast function and decrease in bone formation as possible etiologies reviewed in detail elsewhere [105]. Abnormal trabecular bone density has been observed in the absence of focal abnormalities or remodeling and cortical thinning is noted with marrow expansion on CT [81, 82]. Decreased bone density is appreciated qualitatively on radiographic examinations and quantitatively assessed using dual-energy X-ray absorptiometry (DXA) assessment of bone mineral density (BMD). Z-scores from multiple sites are lower for Gaucher disease patients compared with healthy individuals [106]. Bone density has also been observed to increase in response to treatment [28, 107, 108]. Technical difficulties may be encountered in interpreting BMD in younger children, patients with compression fractures, and bone infarction [61]. Nonetheless, BMD retains an important role in predicting the risk of osteonecrosis and pathologic fracture in adult patients [109].

\section{Osseous complications}

Progressive osseous involvement in type 1 Gaucher disease may begin with painful bone crises that may eventually result in osteonecrosis (also termed avascular necrosis and bone infarction) in about half of patients that may be attributed to packing of the marrow with Gaucher cells leading to thrombosis in situ within the marrow [57, 110]. Osteonecrosis most commonly involves the femoral head and neck, proximal humeri, tibias, and vertebrae [22]. Upper extremity involvement seems to occur in patients with greater global bone marrow involvement [78]. Incumbent pathologic fractures occur in about one-tenth to one-quarter of patients and often require specialized orthopedic management including arthroplasty detailed elsewhere [110-113]. The frequency of osseous complications is thought to mirror that of other organ involvement severity; one study 
showed a significant difference in liver volumes between patients with and without osteonecrosis [56]. Prior to the advent of ERT, thoracic kyphosis and vertebral body collapse following severe osteopenia were commonly noted complications in affected children with resultant morbidity and deformity [114]. Bone crises are now infrequently encountered in pediatric patients in the era of ERT [10]. Osteomyelitis is a relatively infrequent complication noted in $6 \%$ of patients in one cohort [110].

Radiographic detection of early osseous complications such as osteonecrosis and bone infarct may be difficult, often being occult on initial imaging with subsequent development periosteal reaction that may be confused with osteomyelitis ("pseudo-osteomyelitis") [22, 67]. Focal accumulation can result in lytic lesions visible radiographically [32]. Later stages of osteonecrosis demonstrate serpentine sclerosis radiographically. Radiographs are helpful, however, in the initial workup of acute pain to assess for pathologic fracture [115]. Late sequelae including collapse of the femoral heads, proximal humeri, and vertebral bodies can also be appreciated on radiographs along with early onset osteoarthritis [10].

Given these limitations, assessment of acute osseous complications is best performed with initial radiographs followed by prompt MRI assessment [72]. Bone crises may be seen with focal marrow edema on fluid-sensitive sequences [10]. With progressive ischemic insults, osteonecrosis can develop and is evident as T1-weighted hypointense signal with heterogeneous $\mathrm{T} 2$-weighted hyperintense signal often with a "double line" of low and high signal reflecting bone infarction [67]. This focal bone involvement can progress further with collapse of the femoral heads and vertebral bodies encountered in severe marrow disease [10]. Other associated complications can be seen including cortical disruption and subperiosteal hemorrhage (Fig. 10) in the setting of massive medullary expansion and cortical thinning, which may also mimic osteomyelitis [116, 117].

Bone-related malignancies may be slightly more common in Gaucher disease, perhaps related to osteonecrosis as a predisposing factor. MRI may often be warranted for evaluation of discrete lytic lesions given the incidence of malignant bone lesions such as multiple myeloma, osseous lymphoma, sarcomas, and malignant epithelioid hemangioendothelioma [118-120]. Particular attention should be paid to enlarging lesions and those with morphology dissimilar to more common Gaucher disease-related osteopenia, marrow infiltration, and osteonecrosis.

\section{Cardiopulmonary involvement Pulmonary infiltration}

As with the liver, spleen, and bone marrow, Gaucher cells can infiltrate in the lungs, typically depositing within interstitial spaces. Such lung involvement is quite rare, more common in the neuronopathic type, nd not likely to occur as an initial manifestation of this disease [10]. Reticulonodular opacities may be seen on chest radiography, but chest $\mathrm{CT}$ evaluation is more useful in depicting centrilobular nodules, ground glass opacities, interstitial, and bronchial wall thickening [22].

\section{Pulmonary hypertension}

There are multiple proposed etiologies for pulmonary hypertension in Gaucher patients. Pulmonary hypertension is attributable to perivascular infiltration of Gaucher cells or secondary to hepatic disease [22]. An early
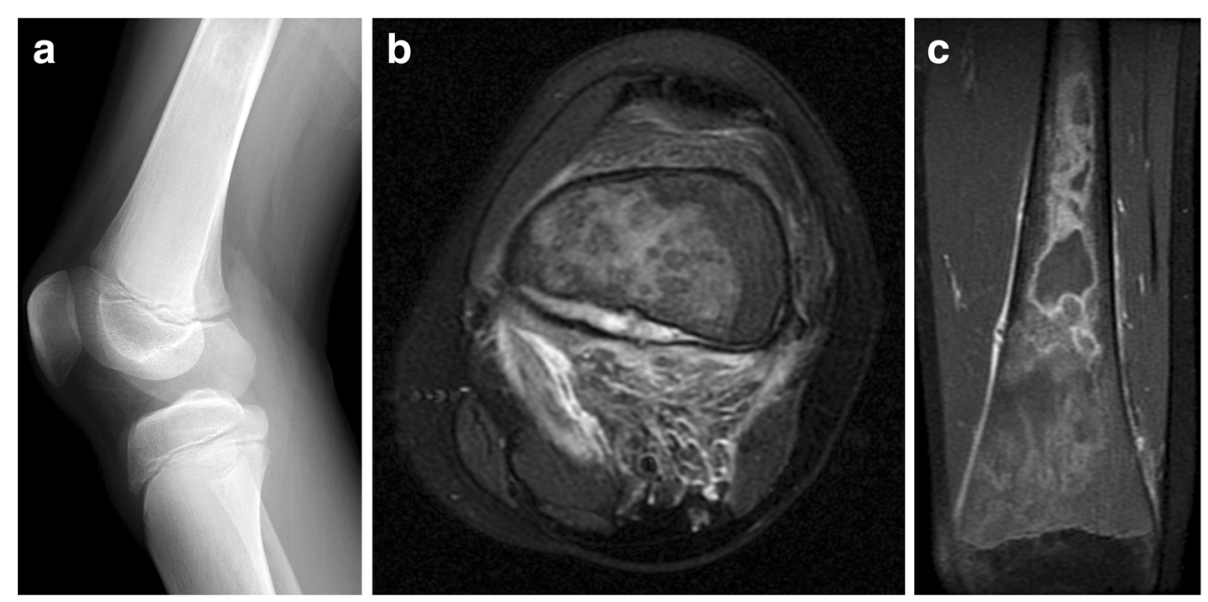

Fig. 10 Bone infarct and subperiosteal hemorrhage mimicking osteomyelitis in Gaucher disease. A 13-year-old male presented with atraumatic knee pain and swelling. Initial lateral knee radiograph (a) showed subtle periosteal reaction along the posterior metadiaphysis of the distal femur and illdefined intramedullary sclerosis within the femoral shaft. Follow-up MRI demonstrated intramedullary marrow edema and focal subperiosteal fluid with surrounding inflammatory changes in the popliteal fossa thought to be related to subperiosteal hemorrhage on axial T2-weighted image (b). Coronal post-contrast $\mathrm{T} 1$ fat-saturated image (c) demonstrated peripheral serpentine enhancement of areas of bone infarction within the distal femur. The patient was subsequently diagnosed with Gaucher disease after initial workup for hematopoietic malignancy 
report of echocardiography in 134 adult Gaucher disease patients identified pulmonary hypertension in approximately one in ten treated patients and none in untreated patients, raising concern for possible treatment-related pulmonary hypertension [121]; however, a subsequent follow-up of children screened with echocardiography did not find pulmonary hypertension in this younger patient population [122]. Therefore, routine screening of pediatric Gaucher disease patients for pulmonary hypertension is not indicated.

\section{Cardiac involvement}

The extent of cardiac involvement in Gaucher disease is uncertain with small numbers of mitral valve prolapse and valvular calcifications reported in a few patients with homozygous D409H mutations [123]. Given the infrequent occurrence of cardiac involvement, most authors only recommend baseline echocardiographic screening in children with Gaucher disease to exclude abnormalities with others also recommending follow-up echocardiography in children with homozygous $\mathrm{D} 409 \mathrm{H}$ mutations $[122,123]$. A more recent investigation of cardiac MRI in a small number of Gaucher disease patients noted left atrial enlargement in three of nine patients [124], and others have implied an association between Gaucher disease and left ventricular diastolic dysfunction on echocardiography, suggesting myocardial infiltration as a possible etiology [125]. Further systematic investigation is needed to assess the frequency of cardiac involvement in Gaucher disease, and the possible relevance of imaging for screening for subclinical disease.

\section{Recommended imaging protocols}

There is a clear need for an objective and reproducible scoring system capable of assessing disease severity to standardize patient monitoring. While clinical scoring methods (PGS3 and GD-DS3) are useful tools for estimating disease severity, these scoring methods do not assess diffuse hepatic disease such as fibrosis, iron accumulation, fat infiltration, and portal hypertension, nor do they assess the full extent of asymptomatic marrow involvement with inclusion of only subjective imaging assessment of marrow involvement.

While ultrasound is affordable and may be sufficient for the assessment of organ volumes and liver lesion screening, there is increasing use of MRI in Gaucher disease with most authorities considering MRI the standard of care [24, 45]. As highlighted throughout this article, there are additional findings on newer imaging methods worth assessing in Gaucher disease patients that cannot be imaged using conventional MRI, ultrasound, and/or radiography. For this reason, we advocate the routine use of an MRI protocol that provides both qualitative and quantitative information of multiple organ systems to provide a comprehensive assessment of disease involvement in Gaucher disease. In younger children under the age of 6 years, sedation may be needed to perform MRI; abbreviated protocols, child life, and distraction techniques may reduce the need for sedation in children [23]. In institutions where particular resources are constrained or unavailable, suitable alternative imaging techniques may be employed acknowledging potential limitations summarized in Table 4. Some examples of alternatives to MRI-based modalities include carefully acquired ultrasound measurements of organ volumes using standardized methods by selected readers and ultrasound elastography methods. However, reliable determination of marrow infiltration requires MRI or nuclear medicine studies.

\section{Liver and spleen MRI}

Diagnostic imaging of hepatic and splenic involvement should consist of sequences tailored for volumetric organ measurement and screening for focal lesions. In conjunction with these conventional acquisitions, MR elastography should be considered, when available, to provide non-invasive assessment of liver and splenic stiffness. While the role of elastography in the clinical management of hepatic fibrosis in Gaucher disease is not yet established, acquisition of organ stiffness measurements may afford insights into disease and treatment effects in the future with wider clinical adoption. It is important to note that elastography results should be interpreted in the context of known limitations including inaccuracy of gradient recalled echo(GRE)-based elastography in patients with iron deposition and massive ascites [42]; as such, performance of both GRE and spin-echo echo-planar imaging elastography sequences is recommended. In addition, assessment of fat fractions and iron quantification may be helpful in providing additional quantitative information for disease severity and treatment response assessment, although these methods also require additional validation in larger populations.

Newer proton density fat fraction (PDFF) sequences allow for single breath-hold acquisition of the entire liver to provide triglyceride fat fractions, $\mathrm{R}^{*}$ mapping, and some also provide automated liver volumes (mDIXON Quant, Philips Healthcare; LiverLab, Siemens Healthineers; IDEAL-IQ, GE Healthcare) [126-128]. These measurements are reliable and highly reproducible across vendors, making them ideal for multi-center investigations that are essential in studying rare conditions such as Gaucher disease [127, 128]. However, these measurement packages often require significant capital and are not yet widely available outside of major research institutions.

Single-voxel MRS for fat fraction measurement may also be considered as a supplement or alternative if 
PDFF sequences are not available. DWI is included in our protocol as it may also be provide indirect assessment of organ cellularity with ADC as a possible quantitative marker of disease severity [37].

If suspicious focal lesions are noted on this surveillance evaluation, dedicated lesion work-up with dynamic hepatocyte-specific contrast-enhanced MRI, multiphase contrast-enhanced CT, or contrast-enhanced ultrasound should be recommended, depending on institutional resources $[54,129,130]$.

\section{Bone marrow MRI}

Qualitative imaging of both the axial (lumbar spine) and appendicular skeleton (proximal femurs) is important for assessment of global marrow involvement, as these sites may respond differently to treatment [64]. While a few recent studies have explored the use of whole-body MRI to screen the entire skeleton, none of the cases of humeral involvement were asymptomatic and therefore screening of the upper extremities may be less salient [78]. As emphasized throughout this article, quantitative measurement of bone marrow fat fractions is of increasing importance in estimating disease severity and tracking treatment response. Similar PDFF acquisitions (mDIXON Quant, Philips Healthcare; LiverLab, Siemens Healthineers; IDEAL-IQ, GE Healthcare) employed to measure fat fractions in the liver may be employed to measure fat fractions in the proximal femur (neck) and lumbar spine (L5), although marrow measurements using these sequences have not been validated in Gaucher disease [88]. Single-voxel MRS is a reliable alternative quantitative method that has been used in Gaucher disease and shows good concordance with Dixon-based methods [92, 131], although acquisition times may be greater for this method. MRS additionally requires expertise in analysis for fat fraction determination, but may be more reliable for lower fat fractions. Both PDFF and MRS generally require the contributions of a medical physicist dedicated to the successful implementation of these protocols. Therefore, institutions without such expertise in quantitative imaging may rely on conventional acquisitions and subjective assessment of marrow involvement by radiologists familiar with semi-quantitative scoring methods such as BMB.

\section{Frequency of comprehensive MRI evaluation}

Discrete parameters for the frequency of follow-up of Gaucher disease patients with imaging are informed by consensus recommendations and institution-specific practices [18, 24, 132, 133]. Comprehensive imaging evaluation of the liver, spleen, and bone marrow of the femurs and lumbar spine should be performed at initial diagnosis, annually for asymptomatic, untreated pediatric patients and biannually for asymptomatic, untreated adults. While some recommend less frequent skeletal imaging evaluation of asymptomatic patients, subclinical marrow involvement appears to be relatively common and asymptomatic individuals may benefit from regular monitoring $[24,58]$. Abdominal imaging is generally recommended on a more frequent basis, every 6 months, in younger pediatric patients [18]. Given the convenience of the previously described comprehensive MRI evaluation (when appropriate sequences and equipment are available) and the observation that musculoskeletal complications indicative of treatment failure sometimes only brought to clinical attention by serial imaging [110], we recommend annual MRI of the bone marrow and abdominal organs. Follow-up evaluation in actively treated patients is typically performed annually as well, although marrow responses may plateau after 4 to 5 years of successful therapy [24, 93]. Ultimately, the frequency and nature of imaging follow-up may need to be adjusted on an individual basis dependent on the availability of imaging techniques, severity of involvement, and trends on prior imaging assessments.

\section{Bone density assessment}

As part of clinical severity scoring and recommended care for patients, bone mineral density measurement is recommended beginning at 6 years of age with follow-up obtained every 1 to 2 years [14, 18, 31]. DXA in children should be performed at institutions with technical and interpretive expertise specific to pediatric populations $[18,23]$. DXA may be performed less frequently in adults depending on extent of marrow infiltration and risk of osteoporosis-related complications.

\section{Assessment of bone complications}

Regional radiographic assessment of acute bone pain should be the first-line examination to assess for the presence of pathologic fracture [24]. However, we advocate a low threshold for the evaluation of affected osseous structures with MRI, given the markedly improved sensitivity for osteonecrosis and collapse [72].

\section{Other imaging assessments}

Decisions regarding routine imaging assessment of cardiac abnormalities with echocardiography and cardiac MRI are beyond the scope of this review with some authors recommending baseline echocardiographic screening in all ages at diagnosis and follow-up evaluation in adults on treatment [121, 122]. These clinical approaches to cardiac involvement may be best individually tailored on the basis of clinical presentation and genotype in the absence of more definitive evidence to support widespread use. Chest CT is valuable in the assessment of patients with suspected primary pulmonary involvement or secondary hepatopulmonary 
syndrome and may be helpful in symptomatic patients, but routine use of chest CT is not recommended due to the rarity of these abnormalities in asymptomatic type 1 patients [10].

\section{Conclusions}

Conventional imaging of non-neuronopathic Gaucher disease underestimates multisystem organ involvement in Gaucher disease, and recent clinical and experimental evidence shows a significant role of multifaceted processes of inflammation, chemotaxis, iron deposition, and fibrosis, even in treated patients. Quantitative bone marrow fat fraction measurements have been touted as a reliable marker of skeletal involvement for treatment response assessment but have been relegated to selected academic medical centers previously. Newer commercially available quantitative MRI methods enable efficient quantification of liver, spleen, and bone marrow fat fraction values and a comprehensive imaging protocol is introduced in this article to take advantage of this opportunity to better characterize this complex disease and guide personalized therapy.

\section{Abbreviations}

ADC: Apparent diffusion coefficient; BMB: Bone marrow burden; BMD: Bone mineral density; CCL18: Chemokine ligand 18; DWI: Diffusion-weighted imaging; ERT: Enzyme replacement therapy; GBA: Glucocerebrosidase; GDDS3: Gaucher Disease Type 1 Severity Scoring System; HCC: Hepatocellular carcinoma; MRE: Magnetic resonance elastography; MRS: Magnetic resonance spectroscopy; PDFF: Proton density fat-fraction; PGS3: Pediatric Gaucher Severity Scoring System; QCSI: Quantitative chemical shift imaging; SMRI: Spanish MRI; SRT: Substrate reduction therapy; SWE: Shear wave elastography; TE: Transient elastography

\section{Acknowledgements}

The authors thank Cauleen Nöel, PhD for her writing assistance in editing the manuscript.

\section{Funding}

Some of the included imaging studies were made possible through the support of a Society of Pediatric Radiology Research and Education Foundation Seed Grant (2018).

\section{Availability of data and materials}

Not applicable.

\section{Authors' contributions}

AJD conceptualized the manuscript and was the main contributor in writing the manuscript. VMHF and CAB contributed to the imaging portions of this review. SDS and DJW provided assistance with protocol development and contributed technical expertise. RCAN and CF contributed clinical expertise. All authors provided edits, read, and approved the final manuscript.

\section{Ethics approval and consent to participate}

The Institutional Review Board (local ethics committee) of Children's Hospita of Philadelphia approved the review and publication of clinical studies, IRB 18-015509.

\section{Consent for publication}

De-identified images included in this manuscript are permitted through local ethics committee approval.

\section{Competing interests}

CF has received consulting fees and/or honoraria from Genzyme corporation Pfizer Inc., and Shire Pharmaceutical, makers of therapies for Gaucher disease. The remaining authors declare that they have no competing interests.

\section{Publisher's Note}

Springer Nature remains neutral with regard to jurisdictional claims in published maps and institutional affiliations.

\section{Author details}

'Department of Radiology, Children's Hospital of Philadelphia, 3401 Civic Center Blvd., Philadelphia, PA 19104, USA. ²Department of Radiology, Perelman School of Medicine at the University of Pennsylvania, 3400 Civic Center Blvd., Philadelphia, PA 19104, USA. ${ }^{3}$ Division of Human Genetics, The Children's Hospital of Philadelphia, Colket Translational Research Building, 3501 Civic Center Blvd, Floor 9, Philadelphia, PA 19104, USA. ${ }^{4}$ Department of Pediatrics, Perelman School of Medicine at the University of Pennsylvania, 3400 Civic Center Blvd., Philadelphia, PA 19104, USA.

Received: 20 March 2019 Accepted: 29 April 2019

Published online: 10 July 2019

\section{References}

1. Thomas AS, Mehta A, Hughes DA (2014) Gaucher disease: haematological presentations and complications. Br J Haematol 165(4):427-440

2. Meikle PJ, Hopwood JJ, Clague AE, Carey WF (1999) Prevalence of lysosomal storage disorders. JAMA. 281(3):249-254

3. Zimran A (2011) How I treat Gaucher disease. Blood. 118(6):1463-1471

4. Dandana A, Ben Khelifa S, Chahed $H$, Miled A, Ferchichi S (2016) Gaucher disease: clinical, biological and therapeutic aspects. Pathobiology. 83(1):13-23

5. Mercimek-Mahmutoglu S, Gruber S, Rolfs A et al (2007) Neurological and brain MRS findings in patients with Gaucher disease type 1. Mol Genet Metab 91(4):390-395

6. Gruber S, Bogner W, Stadlbauer A, Krssak M, Bodamer O (2011) Magnetic resonance spectroscopy in patients with Fabry and Gaucher disease. Eur J Radiol 79(2):295-298

7. Aflaki E, Westbroek W, Sidransky E (2017) The complicated relationship between Gaucher disease and parkinsonism: insights from a rare disease. Neuron. 93(4):737-746

8. Grabowski GA (2008) Phenotype, diagnosis, and treatment of Gaucher's disease. Lancet. 372(9645):1263-1271

9. Cassinerio E, Graziadei G, Poggiali E (2014) Gaucher disease: a diagnostic challenge for internists. Eur J Intern Med. 25(2):117-124

10. McHugh K, Olsen E ØE, Vellodi A (2004) Gaucher disease in children: radiology of non-central nervous system manifestations. Clin Radiol 59(2): 117-123

11. Horowitz M, Pasmanik-Chor M, Borochowitz Z et al (1998) Prevalence of glucocerebrosidase mutations in the Israeli Ashkenazi Jewish population. Hum Mutat 12(4):240-244

12. Beutler E, Nguyen NJ, Henneberger MW et al (1993) Gaucher disease: gene frequencies in the Ashkenazi Jewish population. Am J Hum Genet 52(1):85-88

13. Weinreb NJ, Cappellini MD, Cox TM et al (2010) A validated disease severity scoring system for adults with type 1 Gaucher disease. Genet Med. 12(1):44-51

14. Kallish S, Kaplan P (2013) A disease severity scoring system for children with type 1 Gaucher disease. Eur J Pediatr 172(1):39-43

15. Weinreb NJ, Finegold DN, Feingold E et al (2015) Evaluation of disease burden and response to treatment in adults with type 1 Gaucher disease using a validated disease severity scoring system (DS3). Orphanet J Rare Dis 10:64

16. Belmatoug N, Di Rocco M, Fraga C et al (2017) Management and monitoring recommendations for the use of eliglustat in adults with type 1 Gaucher disease in Europe. Eur J Intern Med 37:25-32

17. Shemesh E, Deroma L, Bembi B et al (2015) Enzyme replacement and substrate reduction therapy for Gaucher disease. Cochrane Database Syst Rev (3):CD010324

18. Kaplan P, Baris H, De Meirleir L et al (2013) Revised recommendations for the management of Gaucher disease in children. Eur J Pediatr 172(4):447-458

19. Di Rocco M, Andria G, Bembi B et al (2012) Minimal disease activity in Gaucher disease: criteria for definition. Mol Genet Metab 107(3):521-525

20. de Fost M, Hollak CE, Groener JE et al (2006) Superior effects of high-dose enzyme replacement therapy in type 1 Gaucher disease on bone marrow 
involvement and chitotriosidase levels: a 2-center retrospective analysis. Blood. 108(3):830-835

21. Vom Dahl S, Poll L, Di Rocco M et al (2006) Evidence-based recommendations for monitoring bone disease and the response to enzyme replacement therapy in Gaucher patients. Curr Med Res Opin 22(6): 1045-1064

22. Katz R, Booth T, Hargunani R, Wylie P, Holloway B (2011) Radiological aspects of Gaucher disease. Skeletal Radiol 40(12):1505-1513

23. Maas M, Hangartner T, Mariani G et al (2008) Recommendations for the assessment and monitoring of skeletal manifestations in children with Gaucher disease. Skeletal Radiol 37(3):185-188

24. Charrow J, Esplin JA, Gribble TJ et al (1998) Gaucher disease: recommendations on diagnosis, evaluation, and monitoring. Arch Intern Med 158(16):1754-1760

25. Adar T, Ilan Y, Elstein D, Zimran A (2018) Liver involvement in Gaucher disease-review and clinical approach. Blood Cells Mol Dis 68:66-73

26. Pandey MK, Jabre NA, Xu YH, Zhang W, Setchell KD, Grabowski GA (2014) Gaucher disease: chemotactic factors and immunological cell invasion in a mouse model. Mol Genet Metab 111(2):163-171

27. Weinreb NJ, Barbouth DS, Lee RE (2018) Causes of death in 184 patients with type 1 Gaucher disease from the United States who were never treated with enzyme replacement therapy. Blood Cells Mol Dis 68:211-217

28. Lukina E, Watman N, Arreguin EA et al (2010) Improvement in hematological, visceral, and skeletal manifestations of Gaucher disease type 1 with oral eliglustat tartrate (Genz-112638) treatment: 2-year results of a phase 2 study. Blood. 116(20):4095-4098

29. Zimran A, Gonzalez-Rodriguez DE, Abrahamov A et al (2015) Safety and efficacy of two dose levels of taliglucerase alfa in pediatric patients with Gaucher disease. Blood Cells Mol Dis 54(1):9-16

30. Pastores GM, Weinreb NJ, Aerts $\mathrm{H}$ et al (2004) Therapeutic goals in the treatment of Gaucher disease. Semin Hematol 41(4 Suppl 5):4-14

31. Yang AC, Bier L, Overbey JR et al (2017) Early manifestations of type Gaucher disease in presymptomatic children diagnosed after parental carrier screening. Genet Med 19(6):652-658

32. Green BA, Alexander AA, Hill PR, Lowe LH (2011) Imaging findings in pediatric type 1 Gaucher disease: what the clinician needs to know. J Pediatr Hematol Oncol 33(4):301-305

33. Elstein D, Tiomkin M, Hadas-Halpern I, Zimran A (2011) Organ volume by computed tomography correlates with longitudinal axis on ultrasound in patients with Gaucher disease. Ultrasound Q 27(4):225-228

34. Patlas M, Hadas-Halpern I, Abrahamov A, Zimran A, Elstein D (2002) Repeat abdominal ultrasound evaluation of 100 patients with type I Gaucher disease treated with enzyme replacement therapy for up to 7 years. Hematol J 3(1):17-20

35. Bracoud L, Ahmad H, Brill-Almon E, Chertkoff R (2011) Improving the accuracy of MRI spleen and liver volume measurements: a phase III Gaucher disease clinical trial setting as a model. Blood Cells Mol Dis 46(1):47-52

36. Lewis S, Dyvorne H, Cui Y, Taouli B (2014) Diffusion-weighted imaging of the liver: techniques and applications. Magn Reson Imaging Clin N Am 22(3):373-395

37. Razek AAKA, Abdalla A, Barakat T, El-Taher H, Ali K (2018) Assessment of the liver and spleen in children with Gaucher disease type I with diffusionweighted MR imaging. Blood Cells Mol Dis 68:139-142

38. Lachmann RH, Wight DG, Lomas DJ et al (2000) Massive hepatic fibrosis in Gaucher's disease: clinico-pathological and radiological features. QJM. 93(4): 237-244

39. Hadas-Halpern I, Deeb M, Abrahamov A, Zimran A, Elstein D (2010) Gaucher disease: spectrum of sonographic findings in the liver. J Ultrasound Med 29(5):727-733

40. Bohte $A E$, van Dussen L, Akkerman EM et al (2013) Liver fibrosis in type Gaucher disease: magnetic resonance imaging, transient elastography and parameters of iron storage. PLoS One 8(3):e57507

41. Rosenbloom BE, Weinreb NJ (2013) Gaucher disease: a comprehensive review. Crit Rev Oncog 18(3):163-175

42. Kennedy P, Wagner M, Castéra L et al (2018) Quantitative Elastography methods in liver disease: current evidence and future directions. Radiology. 286(3):738-763

43. Webb M, Zimran A, Dinur T et al (2018) Are transient and shear wave elastography useful tools in Gaucher disease? Blood Cells Mol Dis 68:143-147

44. Serai SD, Naidu AP, Andrew Burrow T, Prada CE, Xanthakos S, Towbin A (2018) Correlating liver stiffness with disease severity scoring system (DS3) values in Gaucher disease type 1 (GD1) patients. Mol Genet Metab 123(3): 357-363

45. Stein P, Yu H, Jain D, Mistry PK (2010) Hyperferritinemia and iron overload in type 1 Gaucher disease. Am J Hematol 85(7):472-476

46. Poll LW, Koch JA, Willers R et al (2002) Correlation of bone marrow response with hematological, biochemical, and visceral responses to enzyme replacement therapy of nonneuronopathic (type 1) Gaucher disease in 30 adult patients. Blood Cells Mol Dis 28(2):209-220

47. Queiroz-Andrade M, Blasbalg R, Ortega CD et al (2009) MR imaging findings of iron overload. Radiographics. 29(6):1575-1589

48. Regenboog M, Bohte AE, Akkerman EM, Stoker J, Hollak CEM (2017) Iron storage in liver, bone marrow and splenic Gaucheroma reflects residual disease in type 1 Gaucher disease patients on treatment. Br J Haematol 179(4):635-647

49. de Fost M, Vom Dahl S, Weverling GJ et al (2006) Increased incidence of cancer in adult Gaucher disease in Western Europe. Blood Cells Mol Dis 36(1):53-58

50. Mistry PK, Taddei T, vom Dahl S, Rosenbloom BE (2013) Gaucher disease and malignancy: a model for cancer pathogenesis in an inborn error of metabolism. Crit Rev Oncog 18(3):235-246

51. Hill SC, Damaska BM, Ling A et al (1992) Gaucher disease: abdominal MR imaging findings in 46 patients. Radiology. 184(2):561-566

52. Elstein D, Rosenmann E, Reinus C, Paz J, Altarescu G, Zimran A (2003) Amyloidosis and gastric bleeding in a patient with Gaucher disease. J Clin Gastroenterol 37(3):234-237

53. Kaloterakis A, Filiotou A, Koskinas J et al (1999) Systemic AL amyloidosis in Gaucher disease. A case report and review of the literature. J Intern Med 246(6):587-590

54. Anupindi SA, Biko DM, Ntoulia A et al (2017) Contrast-enhanced US assessment of focal liver lesions in children. Radiographics. 37(6):1632-1647

55. Simpson WL, Hermann G, Balwani M (2014) Imaging of Gaucher disease. World J Radiol 6(9):657-668

56. Terk MR, Esplin J, Lee K, Magre G, Colletti PM (1995) MR imaging of patients with type 1 Gaucher's disease: relationship between bone and visceral changes. AJR Am J Roentgenol 165(3):599-604

57. Pastores GM, Meere PA (2005) Musculoskeletal complications associated with lysosomal storage disorders: Gaucher disease and Hurler-Scheie syndrome (mucopolysaccharidosis type I). Curr Opin Rheumatol 17(1):70-78

58. Balwani M, Fuerstman L, Kornreich R, Edelmann L, Desnick RJ (2010) Type 1 Gaucher disease: significant disease manifestations in "asymptomatic" homozygotes. Arch Intern Med 170(16):1463-1469

59. Aldenhoven M, Sakkers RJ, Boelens J, de Koning TJ, Wulffraat NM (2009) Musculoskeletal manifestations of lysosomal storage disorders. Ann Rheum Dis 68(11):1659-1665

60. Rosenthal DI, Scott JA, Barranger J et al (1986) Evaluation of Gaucher disease using magnetic resonance imaging. J Bone Joint Surg Am 68(6):802-808

61. Maas M, Poll LW, Terk MR (2002) Imaging and quantifying skeletal involvement in Gaucher disease. Br J Radiol 75(Suppl 1):A13-A24

62. Terk MR, Dardashti S, Liebman HA (2000) Bone marrow response in treated patients with Gaucher disease: evaluation by T1-weighted magnetic resonance images and correlation with reduction in liver and spleen volume. Skeletal Radiol 29(10):563-571

63. Beutler E, Kuhl W, Vaughan LM (1995) Failure of alglucerase infused into Gaucher disease patients to localize in marrow macrophages. Mol Med 1(3): 320-324

64. DeMayo RF, Haims AH, McRae MC, Yang R, Mistry PK (2008) Correlation of MRI-based bone marrow burden score with genotype and spleen status in Gaucher's disease. AJR Am J Roentgenol 191(1):115-123

65. Carter A, Rajan PS, Deegan P, Cox TM, Bearcroft P (2012) Quantifying the Erlenmeyer flask deformity. Br J Radiol 85(1015):905-909

66. Faden MA, Krakow D, Ezgu F, Rimoin DL, Lachman RS (2009) The Erlenmeyer flask bone deformity in the skeletal dysplasias. Am J Med Genet A 149A(6):1334-1345

67. States $L J$ (2001) Imaging of metabolic bone disease and marrow disorders in children. Radiol Clin North Am 39(4):749-772

68. Chan BY, Gill KG, Rebsamen SL, Nguyen JC (2016) MR imaging of pediatric bone marrow. Radiographics. 36(6):1911-1930

69. Poll LW, Willers R, Häussinger D, Mödder U, vom Dahl S (2010) MRI bone marrow findings in 63 patients with type I Gaucher disease. Rofo. 182(11):979-985

70. Komninaka V, Kolomodi D, Christoulas D et al (2015) Evaluation of bone involvement in patients with Gaucher disease: a semi-quantitative magnetic resonance imaging method (using $\mathrm{ROI}$ estimation of bone lesion) as an 
alternative method to semi-quantitative methods used so far. Eur J Haematol 95(4):342-351

71. Vlieger EJ, Maas M, Akkerman EM, Hollak CE, Den Heeten GJ (2002) Vertebra disc ratio as a parameter for bone marrow involvement and its application in Gaucher disease. J Comput Assist Tomogr 26(5):843-848

72. Maas M, Kuijper M, Akkerman EM (2011) From Gaucher's disease to metabolic radiology: translational radiological research and clinical practice. Semin Musculoskelet Radiol 15(3):301-306

73. Maas M, van Kuijk C, Stoker J et al (2003) Quantification of bone involvement in Gaucher disease: MR imaging bone marrow burden score as an alternative to Dixon quantitative chemical shift MR imaging-initial experience. Radiology. 229(2):554-561

74. Robertson PL, Maas M, Goldblatt J (2007) Semiquantitative assessment of skeletal response to enzyme replacement therapy for Gaucher's disease using the bone marrow burden score. AJR Am J Roentgenol 188(6):1521-1528

75. Fedida B, Touraine S, Stirnemann J, Belmatoug N, Laredo JD, Petrover D (2015) Bone marrow involvement in Gaucher disease at MRI : what longterm evolution can we expect under enzyme replacement therapy? Eur Radiol 25(10):2969-2975

76. Roca M, Mota J, Alfonso P, Pocovi M, Giraldo P (2007) S-MRI score: a simple method for assessing bone marrow involvement in Gaucher disease. Eur J Radiol 62(1):132-137

77. Laudemann K, Moos L, Mengel E et al (2016) Evaluation of treatment response to enzyme replacement therapy with Velaglucerase alfa in patients with Gaucher disease using whole-body magnetic resonance imaging. Blood Cells Mol Dis 57:35-41

78. Poll LW, Cox ML, Godehardt E, Steinhof V, vom Dahl S (2011) Whole body MRI in type I Gaucher patients: evaluation of skeletal involvement. Blood Cells Mol Dis 46(1):53-59

79. Laudemann K, Moos L, Mengel KE et al (2015) Evaluation of bone marrow infiltration in non-neuropathic Gaucher disease patients with use of wholebody MRI — a retrospective data analysis. Rofo. 187(12):1093-1098

80. Lai JKC, Robertson PL, Goh C, Szer J (2018) Intraobserver and interobserver variability of the bone marrow burden (BMB) score for the assessment of disease severity in Gaucher disease. Possible impact of reporting experience. Blood Cells Mol Dis 68:121-125

81. Rosenthal DI, Mayo-Smith W, Goodsitt MM, Doppelt S, Mankin HJ (1989) Bone and bone marrow changes in Gaucher disease: evaluation with quantitative CT. Radiology. 170(1 Pt 1):143-146

82. Rosenthal DI, Barton NW, McKusick KA et al (1992) Quantitative imaging of Gaucher disease. Radiology. 185(3):841-845

83. Magnaldi S, Longo R, Ukmar M, Zanatta M, Bottega M, Sottocasa GL (1997) Bone marrow relaxation times in Gaucher disease before and after enzyme replacement therapy. Eur Radiol 7(4):486-491

84. Johnson LA, Hoppel BE, Gerard EL et al (1992) Quantitative chemical shift imaging of vertebral bone marrow in patients with Gaucher disease. Radiology. 182(2):451-455

85. Griffith JF, Yeung DK, Chow SK, Leung JC, Leung PC (2009) Reproducibility of MR perfusion and (1)H spectroscopy of bone marrow. J Magn Reson Imaging 29(6):1438-1442

86. Karampinos DC, Ruschke S, Dieckmeyer M et al (2018) Quantitative MRI and spectroscopy of bone marrow. J Magn Reson Imaging 47(2):332-353

87. Astrakas LG, Argyropoulou MI (2016) Key concepts in MR spectroscopy and practical approaches to gaining biochemical information in children. Pediatr Radiol 46(7):941-951

88. Aoki T, Yamaguchi S, Kinoshita S, Hayashida Y, Korogi Y (2016) Quantification of bone marrow fat content using iterative decomposition of water and fat with echo asymmetry and least-squares estimation (IDEAL): reproducibility, site variation and correlation with age and menopause. $\mathrm{Br}$ J Radiol 89(1065):20150538

89. Singhal V, Bredella MA (2019) Marrow adipose tissue imaging in humans. Bone. 118:69-76

90. Singhal V, Miller KK, Torriani M, Bredella MA (2016) Short- and long-term reproducibility of marrow adipose tissue quantification by $1 \mathrm{H}-\mathrm{MR}$ spectroscopy. Skeletal Radiol 45(2):221-225

91. Maas M, Hollak CE, Akkerman EM, Aerts JM, Stoker J, Den Heeten GJ (2002) Quantification of skeletal involvement in adults with type I Gaucher's disease: fat fraction measured by Dixon quantitative chemical shift imaging as a valid parameter. AJR Am J Roentgenol 179(4):961-965

92. Jaramillo D, Bedoya MA, Wang DJ et al (2015) Quantification of bone marrow involvement in treated Gaucher disease with proton MR spectroscopy: correlation with bone marrow MRI scores and clinical status. AJR Am J Roentgenol 204(6):1296-1302

93. Hollak C, Maas M, Akkerman E, den Heeten A, Aerts H (2001) Dixon quantitative chemical shift imaging is a sensitive tool for the evaluation of bone marrow responses to individualized doses of enzyme supplementation therapy in type 1 Gaucher disease. Blood Cells Mol Dis 27(6):1005-1012

94. van Dussen L, Zimran A, Akkerman EM et al (2013) Taliglucerase alfa leads to favorable bone marrow responses in patients with type I Gaucher disease. Blood Cells Mol Dis 50(3):206-211

95. Poll LW, Maas M, Terk MR et al (2002) Response of Gaucher bone disease to enzyme replacement therapy. Br J Radiol 75(Suppl 1):A25-A36

96. Duda SH, Laniado M, Schick F, Strayle M, Claussen CD (1995) Normal bone marrow in the sacrum of young adults: differences between the sexes seen on chemical-shift MR imaging. AJR Am J Roentgenol 164(4):935-940

97. Ishijima H, Ishizaka H, Horikoshi H, Sakurai M (1996) Water fraction of lumbar vertebral bone marrow estimated from chemical shift misregistration on MR imaging: normal variations with age and sex. AJR Am J Roentgenol 167(2): 355-358

98. Liney GP, Bernard CP, Manton DJ, Turnbull LW, Langton CM (2007) Age, gender, and skeletal variation in bone marrow composition: a preliminary study at 3.0 Tesla. J Magn Reson Imaging 26(3):787-793

99. van Dussen L, Akkerman EM, Hollak CE, Nederveen AJ, Maas M (2014) Evaluation of an imaging biomarker, Dixon quantitative chemical shift imaging, in Gaucher disease: lessons learned. J Inherit Metab Dis 37(6): 1003-1011

100. Razek AA, Abdalla A, Fathy A, Megahed A (2013) Apparent diffusion coefficient of the vertebral bone marrow in children with Gaucher's disease type I and III. Skeletal Radiol 42(2):283-287

101. Mariani G, Filocamo M, Giona F et al (2003) Severity of bone marrow involvement in patients with Gaucher's disease evaluated by scintigraphy with 99mTc-sestamibi. J Nucl Med 44(8):1253-1262

102. Mariani G, Perri M, Minichilli F et al (2016) Standardization of MRI and Scintigraphic scores for assessing the severity of bone marrow involvement in adult patients with type 1 Gaucher disease. AJR Am J Roentgenol 206(6): $1245-1252$

103. Erba PA, Minichilli F, Giona F et al (2013) $99 \mathrm{mTc}$-sestamibi scintigraphy to monitor the long-term efficacy of enzyme replacement therapy on bone marrow infiltration in patients with Gaucher disease. J Nucl Med 54(10):1717-1724

104. Phenix CP, Rempel BP, Colobong $K$ et al (2010) Imaging of enzyme replacement therapy using PET. Proc Natl Acad Sci U S A 107(24): 10842-10847

105. van Dussen L, Lips P, Everts VE et al (2011) Markers of bone turnover in Gaucher disease: modeling the evolution of bone disease. J Clin Endocrinol Metab 96(7):2194-2205

106. Pastores GM, Wallenstein S, Desnick RJ, Luckey MM (1996) Bone density in type 1 Gaucher disease. J Bone Miner Res 11(11):1801-1807

107. Bembi B, Ciana G, Mengel E, Terk MR, Martini C, Wenstrup RJ (2002) Bone complications in children with Gaucher disease. Br J Radiol 75(Suppl 1):A37-A44

108. Kamath RS, Lukina E, Watman N et al (2014) Skeletal improvement in patients with Gaucher disease type 1: a phase 2 trial of oral eliglustat. Skeletal Radiol 43(10):1353-1360

109. Khan A, Hangartner T, Weinreb NJ, Taylor JS, Mistry PK (2012) Risk factors for fractures and avascular osteonecrosis in type 1 Gaucher disease: a study from the international collaborative Gaucher group (ICGG) Gaucher registry. J Bone Miner Res 27(8):1839-1848

110. Deegan PB, Pavlova E, Tindall J et al (2011) Osseous manifestations of adult Gaucher disease in the era of enzyme replacement therapy. Medicine (Baltimore) 90(1):52-60

111. Itzchaki M, Lebel E, Dweck A et al (2004) Orthopedic considerations in Gaucher disease since the advent of enzyme replacement therapy. Acta Orthop Scand 75(6):641-653

112. Bubbar V, Heras FL, Amato D, Pritzker KP, Gross AE (2009) Total hip replacement in Gaucher's disease: effects of enzyme replacement therapy. J Bone Joint Surg Br 91(12):1623-1627

113. Clarke LA, Hollak CE (2015) The clinical spectrum and pathophysiology of skeletal complications in lysosomal storage disorders. Best Pract Res Clin Endocrinol Metab 29(2):219-235

114. Katz K, Sabato S, Horev G, Cohen IJ, Yosipovitch Z (1993) Spinal involvement in children and adolescents with Gaucher disease Spine (Phila Pa 1976) 18(3):332-335 
115. Petrover D, Belmatoug N (2009) Skeletal manifestations in Gaucher disease: imaging findings and follow up. Presse Med 38 Suppl 2:232-237

116. Lanir A, Hadar H, Cohen I et al (1986) Gaucher disease: assessment with MR imaging. Radiology. 161(1):239-244

117. Wenstrup RJ, Roca-Espiau M, Weinreb NJ, Bembi B (2002) Skeletal aspects of Gaucher disease: a review. Br J Radiol 75(Suppl 1):A2

118. Bohm P, Kunz W, Horny HP, Einsele H (2001) Adult Gaucher disease in association with primary malignant bone tumors. Cancer. 91(3):457-462

119. Weinreb NJ, Lee RE (2013) Causes of death due to hematological and nonhematological cancers in 57 US patients with type 1 Gaucher disease who were never treated with enzyme replacement therapy. Crit Rev Oncog 18(3):177-195

120. Murugesan V, Lischuk A, Haims A et al (2016) Case series and literature review of skeletal tumors and their incidence in the Gaucher disease population. Am J Hematol 91(7):736-741

121. Elstein D, Klutstein MW, Lahad A, Abrahamov A, Hadas-Halpern I, Zimran A (1998) Echocardiographic assessment of pulmonary hypertension in Gaucher's disease. Lancet. 351(9115):1544-1546

122. Rosengarten D, Abrahamov A, Nir A et al (2007) Outcome of ten years' echocardiographic follow-up in children with Gaucher disease. Eur J Pediatr 166(6):549-551

123. Ayyildiz ZA, Alehan D, Uslu N, Yüce A, Gürakan F (2012) Echocardiographic assessment in children with Gaucher disease receiving enzyme replacement therapy. Anadolu Kardiyol Derg 12(2):191-192

124. Roghi A, Poggiali E, Cassinerio E et al (2017) The role of cardiac magnetic resonance in assessing the cardiac involvement in Gaucher type 1 patients: morphological and functional evaluations. J Cardiovasc Med (Hagerstown) 18(4):244-248

125. Lo ludice F, Barbato A, Muscariello R et al (2015) Left ventricular diastolic dysfunction in type I Gaucher disease: an echo Doppler study. Echocardiography. 32(6):890-895

126. Idilman IS, Aniktar H, Idilman R et al (2013) Hepatic steatosis: quantification by proton density fat fraction with MR imaging versus liver biopsy. Radiology. 267(3):767-775

127. Yokoo T, Serai SD, Pirasteh A et al (2018) Linearity, Bias, and precision of hepatic proton density fat fraction measurements by using MR imaging: a meta-analysis. Radiology. 286(2):486-498

128. Serai SD, Dillman JR, Trout AT (2017) Proton density fat fraction measurements at 1.5- and 3-T hepatic MR imaging: same-day agreement among readers and across two imager manufacturers. Radiology. 284(1): 244-254

129. Bota S, Piscaglia F, Marinelli S, Pecorelli A, Terzi E, Bolondi L (2012) Comparison of international guidelines for noninvasive diagnosis of hepatocellular carcinoma. Liver Cancer 1(3-4):190-200

130. Goodwin MD, Dobson JE, Sirlin CB, Lim BG, Stella DL (2011) Diagnostic challenges and pitfalls in MR imaging with hepatocyte-specific contrast agents. Radiographics. 31(6):1547-1568

131. Shen W, Gong X, Weiss J, Jin Y (2013) Comparison among T1-weighted magnetic resonance imaging, modified Dixon method, and magnetic resonance spectroscopy in measuring bone marrow fat. J Obes 2013:298675

132. Cox TM, Aerts JM, Belmatoug N et al (2008) Management of nonneuronopathic Gaucher disease with special reference to pregnancy, splenectomy, bisphosphonate therapy, use of biomarkers and bone disease monitoring. J Inherit Metab Dis 31(3):319-336

133. Charrow J, Andersson HC, Kaplan P et al (2004) Enzyme replacement therapy and monitoring for children with type 1 Gaucher disease: consensus recommendations. J Pediatr 144(1):112-120

\section{Submit your manuscript to a SpringerOpen ${ }^{\circ}$ journal and benefit from:}

- Convenient online submission

- Rigorous peer review

- Open access: articles freely available online

- High visibility within the field

- Retaining the copyright to your article

Submit your next manuscript at $\boldsymbol{\nabla}$ springeropen.com 